\title{
Radiative Squeezing Flow of Second Grade Fluid with Convective Boundary Conditions
}

\author{
T. Hayat ${ }^{1,2}$, Sumaira Jabeen ${ }^{1}$, Anum Shafiq ${ }^{1 *}$, A. Alsaedi ${ }^{2}$ \\ 1 Department of Mathematics, Quaid-I-Azam University, 45320, Islamabad, 44000, Pakistan, 2 Nonlinear \\ Analysis and Applied Mathematics (NAAM) Research Group, Department of Mathematics, Faculty of \\ Science, King Abdulaziz University, Jeddah, 21589, Saudi Arabia \\ *anumshafiq@ymail.com
}

\begin{abstract}
Influence of magnetohydrodynamic (MHD) flow between two parallel disks is considered. Heat transfer analysis is disclosed due to thermal radiation and convective boundary condition. Appropriate transformations are invoked to obtain the ordinary differential system. This system is solved using homotopic approach. Convergence of the obtained solution is discussed. Variations of embedded parameters into the governing problems are graphically discussed. Skin friction coefficient and Nusselt number are numerically computed and analyzed. It is noticed that temperature profile is increasing function of radiation parameter.
\end{abstract}

\section{Gopenaccess}

Citation: Hayat T, Jabeen S, Shafiq A, Alsaedi A (2016) Radiative Squeezing Flow of Second Grade Fluid with Convective Boundary Conditions. PLoS ONE 11(4): e0152555. doi:10.1371/journal. pone.0152555

Editor: Xiao-Dong Wang, North China Electric Power University, CHINA

Received: December 15, 2015

Accepted: March 16, 2016

Published: April 20, 2016

Copyright: @ 2016 Hayat et al. This is an open access article distributed under the terms of the Creative Commons Attribution License, which permits unrestricted use, distribution, and reproduction in any medium, provided the original author and source are credited.

Data Availability Statement: All relevant data are within the paper.

Funding: The authors have no support or funding to report.

Competing Interests: The authors have declared that no competing interests exist.

\section{Introduction}

Squeezing flow has attracted significant attention of many researchers and scientists due to its paramount applications in various fields such as in bio-mechanics, food processing, mechani$\mathrm{cal}$, industrial and chemical engineering. This phenomenon is also observed in bearings, gears, rolling elements, machine tools, automotive engines, polymer processing, design of lubrication systems (including oil and grease systems) and injection and compression shaping etc. These type of flows are generated in many hydrodynamical machines and tools where vertical velocities or normal stresses are applying due to moving boundary. Stefan [1] was the first who studied the squeezing flows. He presented an adhoc asymptotic solution for flow of Newtonian fluid. Further Mahmood et al. [2] investigated the squeezed flow and heat transfer for viscous fluid towards a porous surface. Mustafa et al. [3] developed analytical solutions for the squeezing flow of nanofluid between the parallel disks. Qayyum et al. [4] examined the unsteady squeezed flow of Jeffery fluid between two parallel disks. Magnetohydrodynamic squeezing flow of second grade fluid between two parallel disks is studied by Hayat et al. [5]. Ganji et al. [6] investigated the magnetohydrodynamic (MHD) squeezed flow between two porous disks. Thermal radiation effects in time-dependent axisymmetric squeezing flow of Jeffery fluid between two parallel disks is analyzed by Hayat et al. [7]. Homotopy perturbation solution of MHD squeezing flow between two porous disks is studied by Domairry and Aziz [8].

Flow of electrically conducting fluid in presence of magnetic field is related to magnetohydrodynamics (MHD). The MHD systems are used in many applications such as power generators, accelerators, droplet filters, the design of heat exchangers, electrostatic filters, the cooling of reactors, pumps etc. Magnetic nanofluid is a fluid with unique characteristics of both liquid 
and magnetic field. Numerous applications involving magnetic nanofluids include drug delivery, contrast enhancement in magnetic resonance imaging and magnetic cell separation. Few representative studies on magnetohydrodynamics (MHD) nanofluid can be consulted through the investigations [9-18]. On the other hand the convective heat transfer has also mobilized substantial interest due to its significance in the industrial and environmental technologies including energy storage, gas turbines, nuclear plants, rocket propulsion, geothermal reservoirs and photovoltaic panels. The convective boundary condition has also attracted some interest and this usually is simulated via a Biot number in the wall thermal boundary condition. Recently Rashidi et al. [19] applied the one parameter continuous group method to investigate similarity solutions of magnetohydrodynamic (MHD) heat and mass transfer flow of viscous fluid over a flat surface with convective boundary condition. Analysis of heat and mass transfer in mixed convective flow towards a vertical flat surface with hydrodynamic slip and thermal convective boundary condition is examined by Rashidi et al. [20]. Bachok et al. [21] considered the stagnation point flow towards a shrinking or stretching surface with the bottom of surface heated through convection from a hot fluid. Magnetohydrodynamic (MHD) three-dimensional flow of an incompressible fluid induced by an exponentially stretching surface with convective boundary condition is investigated by Hayat et al. [22].

The radiation effects in the boundary layer flow is very important due to its application in physics, engineering and industrial fields such as glass production, furnace design, polymer processing, gas cooled nuclear reactors and also in space technology like aerodynamics rockets, missiles, propulsion system, power plants for inter planetary flights and space crafts operating at high temperatures. Hence thermal radiation effects cannot be ignored in such processes. Rosseland approximation is used to describe the radiative heat flux in the energy equation. Hayat et al. [23] examined the two-dimensional magnetohydrodynamic flow of thixotropic fluid towards a stretched surface with variable thermal conductivity and thermal radiation effects. Pal [24] examined the effects of Hall current in magnetohydrodynamic (MHD) flow and heat transfer characteristics of viscous fluid past an unsteady permeable radiative stretching surface. Bhattacharyya et al. [25] analyzed the rate of heat transfer in micropolar fluid flow towards a porous shrinking surface with thermal radiation. Heat transfer analysis in MHD flow of viscous fluid past an exponentially stretching sheet with suction/injection effects is conducted by Mukhopadhyay [26]. Hayat et al. [27] observed the mixed convection stagnation point flow of Maxwell fluid over a surface with convective boundary conditions and thermal radiation. Bhattacharyya [28] considered the MHD radiative flow of Casson fluid over a stretching sheet in the stagnation region. Sheikholeslami et al. [29] reported the effect of thermal radiation and heat transfer by considering two phase model in magnetohydrodynamic nanofluid flow.

The purpose of present paper is to analyze the analytic solution of squeezing flow of second grade fluid between two porous disks. Fluid is electrically conducting in presence of variable magnetic field. Heat transfer is carried out with thermal radiation and convective boundary condition. Series solutions are found by homotopy analysis method [30-40]. Velocity, temperature, skin friction coefficient and Nusselt number are analyzed for different emerging parameters. To check the validity of the solutions, we have presented the comparison of our results for limiting previously published papers [5,8]. An excellent agreement is found.

\section{Formulation}

We examine the incompressible axisymmetric squeezing flow of second-grade fluid between two infinite porous disks (see Fig 1). Heat transfer analysis is carried out by taking thermal radiation and convective boundary condition. The upper disk at $z=H(1-a t)^{\frac{1}{2}}$ is moving 
with velocity $\frac{d z}{d t}=\frac{-1}{2} a H(1-a t)^{\frac{-1}{2}}$ while lower porous disk at $z=0$ is stationary. Mathematically $w=\frac{\partial h}{\partial t}$ represents the squeezing of the upper disk towards the lower disk. Variable magnetic field of inclined character via an angle $\psi$ is applied. The law of conservation of mass, momentum and energy for the considered problem are

$$
\frac{\partial u}{\partial r}+\frac{\partial w}{\partial z}+\frac{u}{r}=0
$$

$$
\begin{aligned}
\rho\left(\frac{\partial u}{\partial t}\right. & \left.+u \frac{\partial u}{\partial r}+w \frac{\partial u}{\partial z}\right) \\
= & -\frac{\partial p}{\partial r}+\mu\left(\frac{\partial^{2} u}{\partial z^{2}}+\frac{1}{r} \frac{\partial u}{\partial r}+\frac{\partial^{2} u}{\partial r^{2}}-\frac{u}{r^{2}}\right)+\alpha\left\{\frac{2}{r} \frac{\partial^{2} u}{\partial r \partial t}-\frac{2}{r^{2}} \frac{\partial u}{\partial t}+2 \frac{\partial^{3} u}{\partial r^{2} \partial t}+\frac{\partial^{3} w}{\partial r \partial z \partial t}+\frac{\partial^{3} u}{\partial z^{2} \partial t}\right. \\
& +2 \frac{u^{2}}{r^{3}}-2 \frac{w}{r^{2}} \frac{\partial u}{\partial z}-\frac{1}{r}\left(\frac{\partial u}{\partial z}\right)^{2}-\frac{\partial u}{\partial z} \frac{\partial^{2} w}{\partial z^{2}}+w \frac{\partial^{3} u}{\partial z^{3}}-2 \frac{u}{r^{2}} \frac{\partial u}{\partial r}+\frac{\partial u}{\partial r} \frac{\partial^{2} u}{\partial z^{2}}+\frac{\partial w}{\partial r} \frac{\partial^{2} w}{\partial z^{2}} \\
& +\frac{1}{r}\left(\frac{\partial w}{\partial r}\right)^{2}+2 \frac{w}{r} \frac{\partial^{2} u}{\partial r \partial z}+\frac{\partial w}{\partial r} \frac{\partial^{2} u}{\partial r \partial z}+2 \frac{\partial w}{\partial z} \frac{\partial^{2} w}{\partial r \partial z}-\frac{\partial u}{\partial r} \frac{\partial^{2} w}{\partial r \partial z}+u \frac{\partial^{3} u}{\partial r \partial z^{2}}+w \frac{\partial^{3} w}{\partial r \partial z^{2}} \\
& \left.+2 \frac{u}{r} \frac{\partial^{2} u}{\partial r^{2}}+2 \frac{\partial u}{\partial r} \frac{\partial^{2} u}{\partial r^{2}}+\frac{\partial u}{\partial z} \frac{\partial^{2} w}{\partial r^{2}}+2 \frac{\partial w}{\partial r} \frac{\partial^{2} w}{\partial r^{2}}+2 w \frac{\partial^{3} u}{\partial r^{2} \partial z}+u \frac{\partial^{3} w}{\partial r^{2} \partial z}+2 u \frac{\partial^{3} u}{\partial r^{3}}\right\} \\
& -\frac{\sigma B_{0}^{2}}{(1-a t)} \sin ^{2} \psi u
\end{aligned}
$$

$$
\begin{aligned}
\rho\left(\frac{\partial w}{\partial t}+u \frac{\partial w}{\partial r}+w \frac{\partial w}{\partial z}\right)= & -\frac{\partial p}{\partial z}+\mu\left(\frac{1}{r} \frac{\partial w}{\partial r}+\frac{\partial^{2} w}{\partial r^{2}}+\frac{\partial^{2} w}{\partial z^{2}}\right)+\alpha\left\{\frac{1}{r} \frac{\partial^{2} u}{\partial z \partial t}+\frac{1}{r} \frac{\partial^{2} w}{\partial r \partial t}\right. \\
& +\frac{\partial^{3} w}{\partial r^{2} \partial t}+\frac{\partial^{3} u}{\partial r \partial z \partial t}+2 \frac{\partial^{3} w}{\partial z^{2} \partial t}-\frac{1}{r} \frac{\partial u}{\partial z} \frac{\partial w}{\partial z}+\frac{w}{r} \frac{\partial^{2} u}{\partial z^{2}} \\
& +2 \frac{\partial u}{\partial z} \frac{\partial^{2} u}{\partial z^{2}}+2 \frac{\partial w}{\partial z} \frac{\partial^{2} w}{\partial z^{2}}+2 w \frac{\partial^{3} w}{\partial z^{3}}+\frac{1}{r} \frac{\partial u}{\partial z} \frac{\partial u}{\partial r}+\frac{1}{r} \frac{\partial w}{\partial z} \frac{\partial w}{\partial r} \\
& +\frac{\partial w}{\partial r} \frac{\partial^{2} u}{\partial z^{2}}-\frac{1}{r} \frac{\partial u}{\partial r} \frac{\partial w}{\partial r}+\frac{u}{r} \frac{\partial^{2} u}{\partial z \partial r}-\frac{\partial w}{\partial z} \frac{\partial^{2} u}{\partial r \partial z}+2 \frac{\partial u}{\partial r} \frac{\partial^{2} u}{\partial r \partial z} \\
& +\frac{w}{r} \frac{\partial^{2} w}{\partial r \partial z}+\frac{\partial u}{\partial z} \frac{\partial^{2} w}{\partial r \partial z}+w \frac{\partial^{3} u}{\partial r \partial z^{2}}+2 u \frac{\partial^{3} w}{\partial r \partial z^{2}}+\frac{\partial u}{\partial z} \frac{\partial^{2} u}{\partial r^{2}} \\
& -\frac{\partial w}{\partial r} \frac{\partial^{2} u}{\partial r^{2}}+\frac{u}{r} \frac{\partial^{2} w}{\partial r^{2}}+\frac{\partial w}{\partial z} \frac{\partial^{2} w}{\partial r^{2}}+u \frac{\partial^{3} u}{\partial r^{2} \partial z}+w \frac{\partial^{3} w}{\partial r^{2} \partial z} \\
& \left.+u \frac{\partial^{3} w}{\partial r^{3}}\right\}-\frac{\sigma B_{0}^{2}}{(1-a t)} \cos ^{2} \psi w
\end{aligned}
$$$$
\rho c_{p}\left(\frac{\partial T}{\partial t}+u \frac{\partial T}{\partial r}+w \frac{\partial T}{\partial z}\right)=k\left(\frac{\partial^{2} T}{\partial r^{2}}+\frac{\partial^{2} T}{\partial z^{2}}+\frac{1}{r} \frac{\partial T}{\partial r}\right)+\frac{16 \sigma^{*} T_{\infty}^{3}}{3 k^{*}}\left(\frac{\partial^{2} T}{\partial r^{2}}+\frac{\partial^{2} T}{\partial z^{2}}+\frac{1}{r} \frac{\partial T}{\partial r}\right),
$$ 


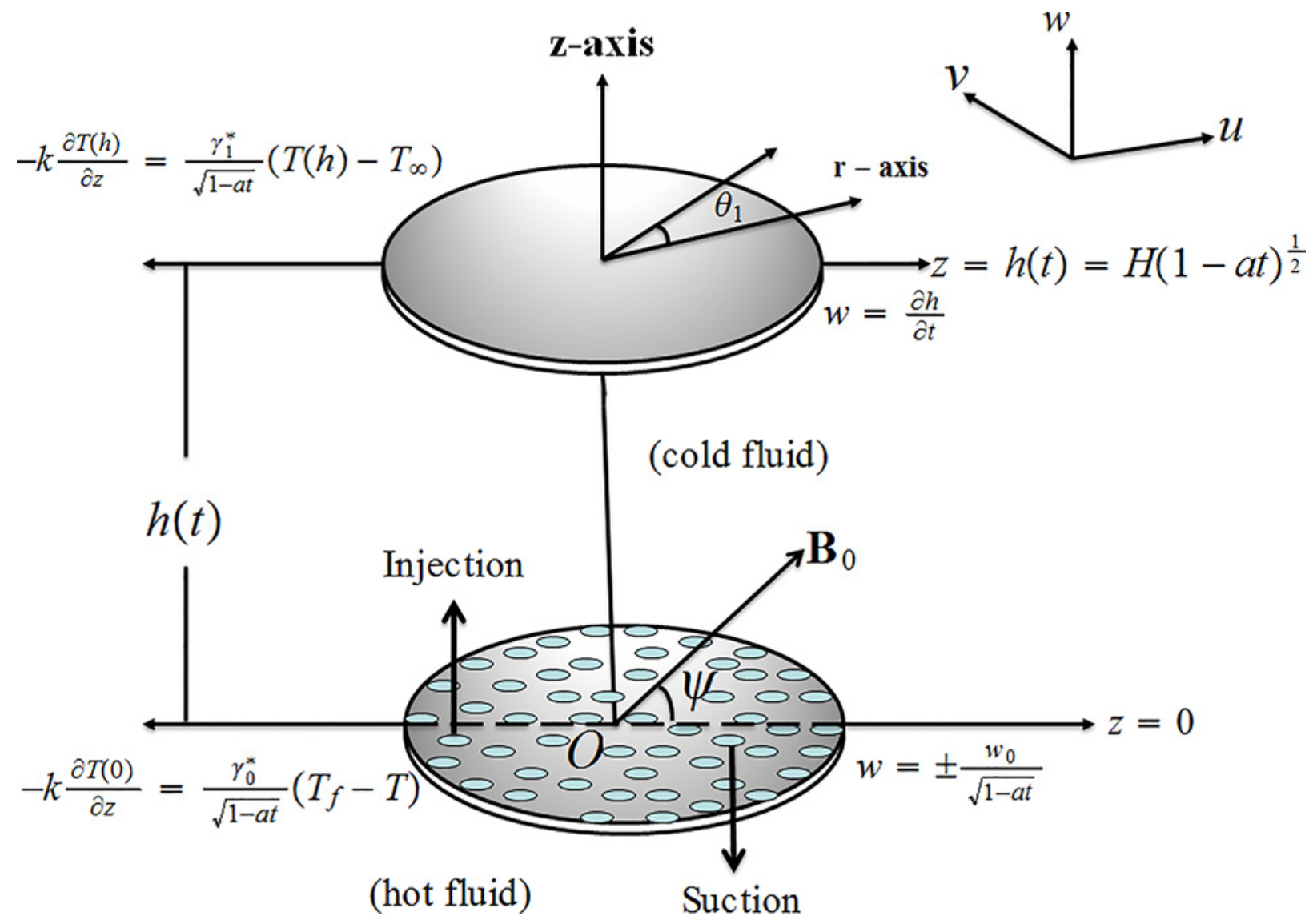

Fig 1. Geometry of problem.

doi:10.1371/journal.pone.0152555.g001

subject to the boundary conditions

$$
\begin{gathered}
u=0, \quad w=\frac{\partial h}{\partial t}, \quad-k \frac{\partial T(h)}{\partial z}=\frac{\gamma_{1}^{*}}{\sqrt{1-a t}}\left(T(h)-T_{\infty}\right) \quad \text { at } z=h(t), \\
u=0, \quad w= \pm \frac{w_{0}}{\sqrt{1-a t}}, \quad-k \frac{\partial T(0)}{\partial z}=\frac{\gamma_{0}^{*}}{\sqrt{1-a t}}\left(T_{f}-T\right) \quad \text { at } z=0 .
\end{gathered}
$$

In the above expressions $u$ and $w$ denote the velocity components in the $r$ and $z$ directions respectively, $\rho$ the fluid density, $\sigma$ the electrical conductivity, $c_{p}$ the specific heat, $\mu$ the dynamic viscosity, $\gamma_{0}^{*}$ the heat transfer coefficient at the lower plate, $\gamma_{1}^{*}$ the rate of heat transfer coefficient of fluid at upper plate, $k$ the thermal conductivity far away from the disk, $\sigma^{*}$ the Stefan-Boltzmann constant and $k^{*}$ the mean absorption coefficient, $w_{0}$ corresponds to the case for suction while $-w_{0}$ leads to the case for blowing. It should be noted that the governing equations are reduced to viscous fluid when $\alpha=0$. 
We consider

$$
\begin{aligned}
u & =\frac{a r}{2(1-a t)} f^{\prime}(\eta), \quad w=-\frac{a H}{\sqrt{1-a t}} f(\eta), \\
B & =\frac{B_{0}}{\sqrt{1-a t}}, \quad \eta=\frac{z}{H \sqrt{1-a t}}, \\
\theta & =\frac{T-T_{\infty}}{T_{f}-T_{\infty}},
\end{aligned}
$$

where $T_{f}$ is the temperature of the hot fluid at the lower permeable disk, $T_{\infty}$ the ambient temperature above the upper disk, $T$ the fluid temperature such that $T_{f}>T$ and $T_{\infty}<T$. The Eq (1) is identically satisfied and Eqs (2-6) take the forms

$$
\begin{gathered}
f^{i v}-S\left(\eta f^{\prime \prime \prime}+3 f^{\prime \prime}-2 f f^{\prime \prime \prime}\right)+\frac{\alpha_{1}}{2}\left(5 f^{i v}+\eta f^{v}-2 f f^{v}\right)-\sin ^{2} \psi M^{2} f^{\prime \prime}=0, \\
\left(1+\frac{4}{3} R\right) \theta^{\prime \prime}(\eta)-S \operatorname{Pr}\left[\eta \theta^{\prime}(\eta)-2 \theta^{\prime}(\eta) f(\eta)\right]=0 \\
f^{\prime}(\eta)=0, \quad f(\eta)=A \quad \theta^{\prime}(\eta)=\gamma_{1}(\theta(0)-1) \quad \text { at } \eta=0 \\
f^{\prime}(\eta)=0, \quad f(\eta)=\frac{1}{2} \quad \theta^{\prime}(\eta)=-\gamma_{2}(\theta(1)) \quad \text { at } \eta=1
\end{gathered}
$$

in which

$$
\begin{aligned}
& M=\sqrt{\frac{\sigma B_{0}^{2} H^{2}}{\mu}}, \quad S=\frac{a H^{2}}{2 v}, \quad \alpha_{1}=\frac{\alpha a}{\mu(1-a t)}, \\
& R=\frac{4 \sigma^{*} T_{\infty}^{3}}{k k^{*}}, \quad \operatorname{Pr}=\frac{\mu c_{p}}{k}, \quad A=\frac{ \pm w_{0}}{a H}, \\
& \gamma_{1}=\frac{\gamma_{0}^{*} H}{k}, \quad \gamma_{2}=\frac{\gamma_{1}^{*} H}{k}
\end{aligned}
$$

where $M$ denotes the magnetic parameter, $S$ the squeezing parameter, $\alpha_{1}$ the dimensionless second grade fluid parameter, $R$ represents radiation parameter and $A$ represents suction/blowing parameter.

The skin friction coefficient and the local Nusselt number are

$$
C_{f r}=\frac{\left.\tau_{r z}\right|_{z=0, h(t)}}{\rho\left(\frac{-a H}{2(1-a t)^{\frac{1}{2}}}\right)^{2}},
$$

where

$\tau_{r z}=\mu\left(\frac{\partial u}{\partial z}+\frac{\partial w}{\partial r}\right)+\alpha\left(\frac{\partial^{2} u}{\partial z \partial t}+u \frac{\partial^{2} u}{\partial r \partial z}+w \frac{\partial^{2} u}{\partial z^{2}}+\frac{\partial^{2} w}{\partial r \partial t}+u \frac{\partial^{2} w}{\partial r^{2}}+w \frac{\partial^{2} w}{\partial r \partial z}-\frac{\partial w}{\partial z} \frac{\partial u}{\partial z}+\frac{\partial w}{\partial z} \frac{\partial w}{\partial r}+\frac{\partial u}{\partial z} \frac{\partial u}{\partial r}-\frac{\partial w}{\partial r} \frac{\partial u}{\partial r}\right)$,

and

$$
N u_{r}=\frac{H q_{w}}{k\left(T_{f}-T_{\infty}\right)}=-\frac{\left.H\left(k+\frac{16 \sigma^{*} T_{\infty}^{3}}{3 k^{*}}\right) \frac{\partial T}{\partial z}\right|_{z=0, h(t)}}{k\left(T_{f}-T_{\infty}\right)} .
$$


In dimensionless form we obtain

$$
\begin{aligned}
& C_{f r 1} \frac{H^{2}}{r^{2}} \operatorname{Re}_{r}=\left(1+\frac{3}{2} \alpha_{1}\right) f^{\prime \prime}(1), \quad C_{f r 0} \frac{H^{2}}{r^{2}} \operatorname{Re}_{r}=\left(1+\frac{3}{2} \alpha_{1}\right) f^{\prime \prime}(0)-\alpha_{1} A f^{\prime \prime \prime}(0), \\
& \sqrt{1-a t} N u_{r 1}=-\theta^{\prime}(1)\left(1+\frac{4}{3} R\right), \quad \sqrt{1-a t} N u_{r 0}=-\theta^{\prime}(0)\left(1+\frac{4}{3} R\right)
\end{aligned}
$$

in which $\operatorname{Re}_{r}=\frac{a r H(1-a t)^{\frac{1}{2}}}{2 v}$ is the local Reynold number, $N u_{r 0}$ denotes the heat transfer rate at lower disk while $N u_{r 1}$ is the heat transfer rate at upper disk. Similarly $C_{f r 1}$ and $C_{f r 0}$ represent the skin friction coefficient at upper and lower disks respectively.

\section{Homotopic Solutions}

In order to find the homotopy analysis solutions we choose the base functions:

$$
\left\{\eta^{n} ; n \geq 0\right\}
$$

and express

$$
\begin{aligned}
& f(\eta)=\sum_{n=0}^{\infty} a_{n} \eta^{n}, \\
& \theta(\eta)=\sum_{n=0}^{\infty} b_{n} \eta^{n},
\end{aligned}
$$

where $a_{n}$ and $b_{n}$ are the coefficients to be determined. The initial guesses $\left(f_{0}, \theta_{0}\right)$ and auxiliary linear operators $\left(\mathbf{L}_{f} \mathbf{L}_{\theta}\right)$ are

$$
\begin{gathered}
f_{0}(\eta)=(-1+2 A) \eta^{3}+3\left(\frac{1}{2}-A\right) \eta^{2}+A, \theta_{0}(\eta)=\frac{\gamma_{1}\left(1+\gamma_{2}-\eta \gamma_{2}\right)}{\gamma_{1}+\gamma_{2}+\gamma_{1} \gamma_{2}} \\
\mathbf{L}_{f}(\eta)=\frac{d^{4} f}{d \eta^{4}}, \mathbf{L}_{\theta}(\eta)=\frac{d^{2} \theta}{d \eta^{2}} \\
\mathbf{L}_{f}\left[C_{1}+C_{2} \eta^{3}+C_{3} \eta^{2}+C_{4} \eta\right]=0 \\
\mathbf{L}_{\theta}\left[C_{5}+C_{6} \eta\right]=0
\end{gathered}
$$

with $C_{i}(i=1-6)$ denote the arbitrary constants. 


\section{Zeroth-order problem}

The zeroth order deformation problems are given below

$$
\begin{gathered}
(1-p) \mathbf{L}_{f}\left[\hat{f}(\eta, p)-f_{0}(\eta)\right]=p \hbar_{f} \mathbf{N}_{f}[\hat{f}(\eta, p)] \\
\left.\frac{\partial \hat{f}(\eta ; p)}{\partial \eta}\right|_{\eta=0}=0,\left.\frac{\partial \hat{f}(\eta ; p)}{\partial \eta}\right|_{\eta=1}=0,\left.\hat{f}(\eta ; p)\right|_{\eta=0}=A,\left.\quad \hat{f}(\eta ; p)\right|_{\eta=1}=\frac{1}{2}, \\
(1-p) \mathbf{L}_{\theta}\left[\hat{\theta}(\eta, p)-\theta_{0}(\eta)\right]=p \hbar_{\theta} \mathbf{N}_{\theta}[\hat{\theta}(\eta, p), \hat{f}(\eta, p)] \\
\left.\frac{\partial \hat{\theta}(\eta ; p)}{\partial \eta}\right|_{\eta=0}=\gamma_{1}(\theta(0)-1),\left.\quad \frac{\partial \hat{\theta}(\eta ; p)}{\partial \eta}\right|_{\eta=1}=-\gamma_{2}(\theta(1)) \\
\mathbf{N}_{f}[\hat{f}(\eta ; p)]=\frac{\partial^{4} \hat{f}(\eta, p)}{\partial \eta^{4}}-S\left(3 \frac{\partial^{2} \hat{f}(\eta, p)}{\partial \eta^{2}}+\eta \frac{\partial^{3} \hat{f}(\eta, p)}{\partial \eta^{3}}-2 \hat{f}(\eta, p) \frac{\partial^{3} \hat{f}(\eta, p)}{\partial \eta^{3}}\right) \\
+\frac{\alpha_{1}}{2}\left(5 \frac{\partial^{4} \hat{f}(\eta, p)}{\partial \eta^{4}}+\eta \frac{\partial^{5} \hat{f}(\eta, p)}{\partial \eta^{5}}-2 \hat{f}(\eta, p) \frac{\partial^{5} \hat{f}(\eta, p)}{\partial \eta^{5}}\right) \\
-\sin ^{2} \psi M^{2} \frac{\partial^{2} \hat{f}(\eta, p)}{\partial \eta^{2}}, \\
\mathbf{N}_{\theta}[\hat{f}(\eta ; p), \hat{\theta}(\eta ; p)]=\left(1+\frac{4}{3} R\right) \frac{\partial^{2} \hat{\theta}(\eta, p)}{\partial \eta^{2}}-\operatorname{Pr} S\left(\eta \frac{\partial \hat{\theta}(\eta, p)}{\partial \eta}-2 \frac{\partial \hat{\theta}(\eta, p)}{\partial \eta} \hat{f}(\eta, p)\right)
\end{gathered}
$$

where, $p \in[0,1]$ represents embedding parameter while $\hbar_{f}$ and $\hbar_{\theta}$ denote non-zero auxiliary parameters.

\section{mth-order deformation problems}

The $m$ th-order deformation problems are

$$
\begin{gathered}
\mathbf{L}_{f}\left[\hat{f}_{m}(\eta)-\chi_{m} \hat{f}_{m-1}(\eta)\right]=\hbar_{f} \mathbf{R}_{m}^{f}(\eta) \\
\left.\frac{\partial \hat{f}_{m}(\eta, p)}{\partial \eta}\right|_{\eta=0}=0,\left.\frac{\partial \hat{f}_{m}(\eta, p)}{\partial \eta}\right|_{\eta=1}=0,\left.\hat{f}_{m}(\eta ; p)\right|_{\eta=0}=0,\left.\hat{f}_{m}(\eta ; p)\right|_{\eta=1}=0 \\
\mathbf{L}_{\theta}\left[\hat{\theta}_{m}(\eta)-\chi_{m} \hat{\theta}_{m-1}(\eta)\right]=\hbar_{\theta} \mathbf{R}_{m}^{\theta}(\eta), \\
\left.\frac{\partial \hat{\theta}_{m}(\eta ; p)}{\partial \eta}\right|_{\eta=0}=0,\left.\frac{\partial \hat{\theta}_{m}(\eta ; p)}{\partial \eta}\right|_{\eta=1}=0,
\end{gathered}
$$




$$
\begin{aligned}
& \mathbf{R}_{m}^{f}(\eta)= f_{m-1}^{i v}(\eta)-S\left(3 f_{m-1}^{\prime \prime}(\eta)+\eta f_{m-1}^{\prime \prime \prime}(\eta)\right)+\frac{\alpha_{1}}{2}\left(5 f_{m-1}^{i v}(\eta)\right. \\
&\left.+\eta f_{m-1}^{v}(\eta)\right)+\sum_{k=0}^{m-1}\left[2 S\left(f_{m-1-k} f_{k}^{\prime \prime \prime}\right)-\alpha_{1} f_{m-1-k} f_{k}^{v}\right] \\
&-\sin ^{2} \psi M^{2} f_{m-1}^{\prime \prime}(\eta), \\
& \mathbf{R}_{m}^{\theta}(\eta)=\left(1+\frac{4}{3} R\right) \theta^{\prime \prime}(\eta)-\operatorname{Pr} S\left(\eta \theta_{m-1}^{\prime}-2 \sum_{k=0}^{m-1} f_{m-1-k} \theta_{k}^{\prime}\right), \\
& \chi_{m}= \begin{cases}0, & m \leq 1 \\
1, & m>1\end{cases}
\end{aligned}
$$

For $p=0$ and $p=1$ one has

$$
\begin{aligned}
& \hat{f}(\eta, 0)=f_{0}(\eta), \quad \hat{f}(\eta, 1)=f(\eta), \\
& \hat{\theta}(\eta, 0)=\theta_{0}(\eta), \quad \hat{\theta}(\eta, 1)=\theta(\eta) .
\end{aligned}
$$

When $p$ varies from 0 to 1 then $\hat{f}(\eta ; p)$ and $\hat{\theta}(\eta ; p)$ start from the initial solutions $f_{0}(\eta)$ and $\theta_{0}(\eta)$ and reach to the final solutions $f(\eta)$ and $\theta(\eta)$ respectively. The values of auxiliary parameters is selected in such a manner that the series solutions converge. The general solutions $\left(f_{m}\right.$, $\left.\theta_{m}\right)$ via special solutions $\left(f_{m}^{*}, \theta_{m}^{*}\right)$ are

$$
\begin{gathered}
f_{m}(\eta)=f_{m}^{*}(\eta)+C_{1}+C_{2} \eta^{3}+C_{3} \eta^{2}+C_{4} \eta, \\
\theta_{m}(\eta)=\theta_{m}^{*}(\eta)+C_{5}+C_{6} \eta,
\end{gathered}
$$

where the $C_{i}(i=1-6)$ are the involved constants.

\section{Analysis of Results}

\section{Convergence of solutions}

It is quite clear that derived series solutions contain the auxiliary parameters $\hbar_{f}$ and $\hbar_{\theta}$ which are very important in controlling and adjusting the convergence. To obtain the admissible values of auxiliary parameters, the $\hbar$ - curves are sketched at $19^{t h}$-order of approximation in Figs 2 and 3. These curves are sketched for different values of second grade fluid parameter $\alpha_{1}$ for both velocity and temperature. These Figs show that meaningful values of $\hbar_{f}$ and $\hbar_{\theta}$ are $-1.3 \leq$ $\hbar_{f}<-0.2$ (for $\alpha_{1}=0.1$ ) and $-0.9 \leq \hbar_{\theta}<-0.2$ (for $\alpha_{1}=0.3$ ). Also Table 1 depicts that the series solutions are convergent up to six decimal places at $8^{\text {th }}$ order of approximation for momentum and $6^{\text {th }}$ order of approximation for temperature. 


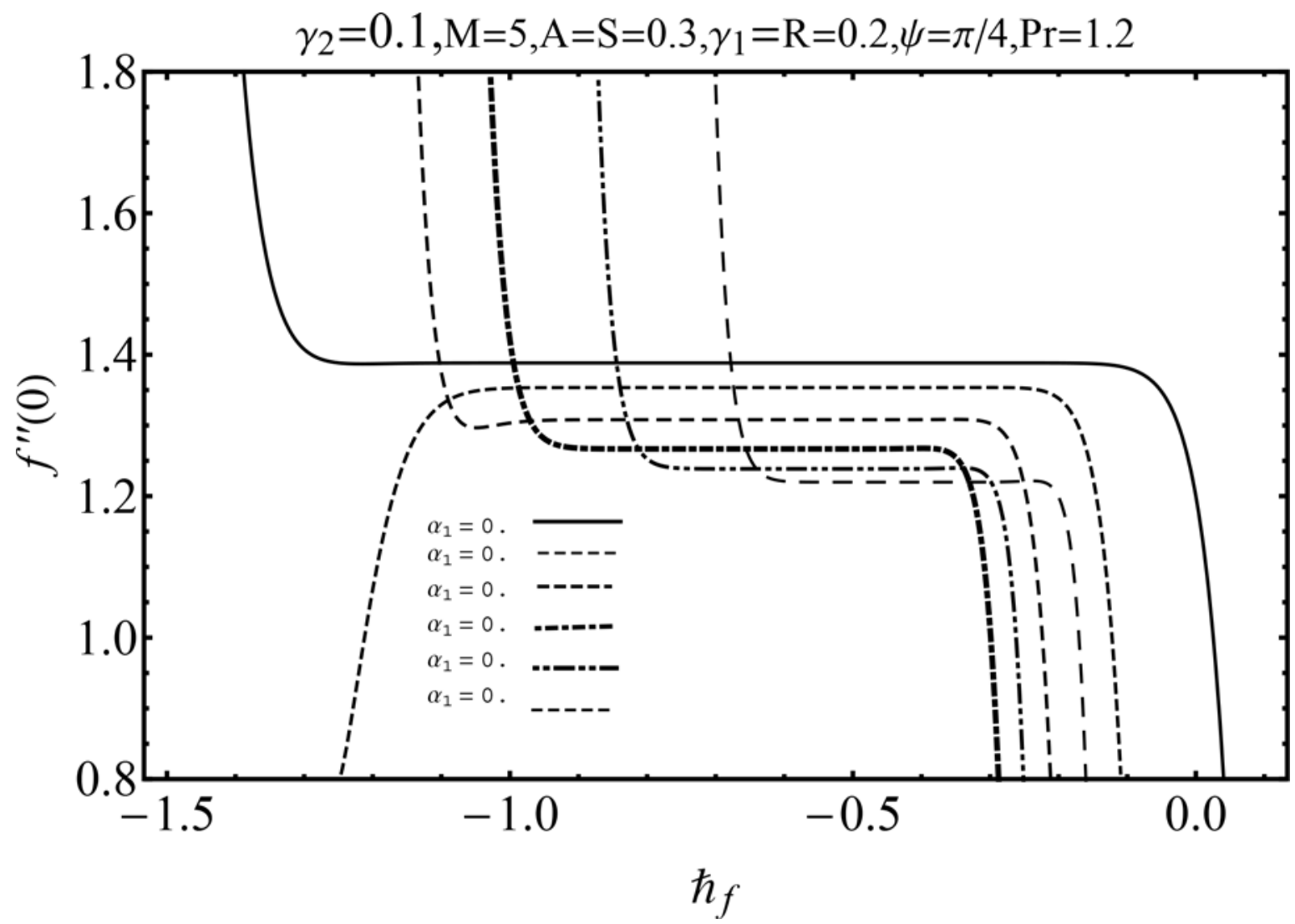

Fig 2. $\hbar$ - curve for $f^{\prime \prime}(0)$ via various values of $\alpha_{1}$.

Residual errors are calculated for momentum and energy equations by using expressions

$$
\begin{aligned}
& \Delta_{m}^{f}=\int_{0}^{1}\left[\mathbf{R}_{m}^{f}\left(\eta, \hbar_{f}\right)\right]^{2} d \eta, \\
& \Delta_{m}^{\theta}=\int_{0}^{1}\left[\mathbf{R}_{m}^{\theta}\left(\eta, \hbar_{\theta}\right)\right]^{2} d \eta .
\end{aligned}
$$

Figs 4 and 5 display the $\hbar$ - curves for residual error of $f$ and $\theta$ in order to get the admissible range for $\hbar$. It is observed that correct result up to 6 th decimal places is obtained by choosing the value of $\hbar$ from this range. Further the series solutions converge in the whole region of $\eta(0<\eta<\infty)$ when $\hbar_{f}=-0.9=\hbar_{\theta}$.

\section{Discussion}

In this subsection, we studied the influence of diverse parameters on the velocity, temperature, skin friction coefficient and local Nusselt number.

\section{Velocity profile}

Effect of magnetic parameter $(M)$ on the velocity distribution $f(\eta)$ in cases of suction and blowing have been displayed through Figs 6 and 7. It is observed that the magnitude of the radial velocity $f(\eta)$ shows dual behavior with the increase in the magnetic parameter $M$. For higher 


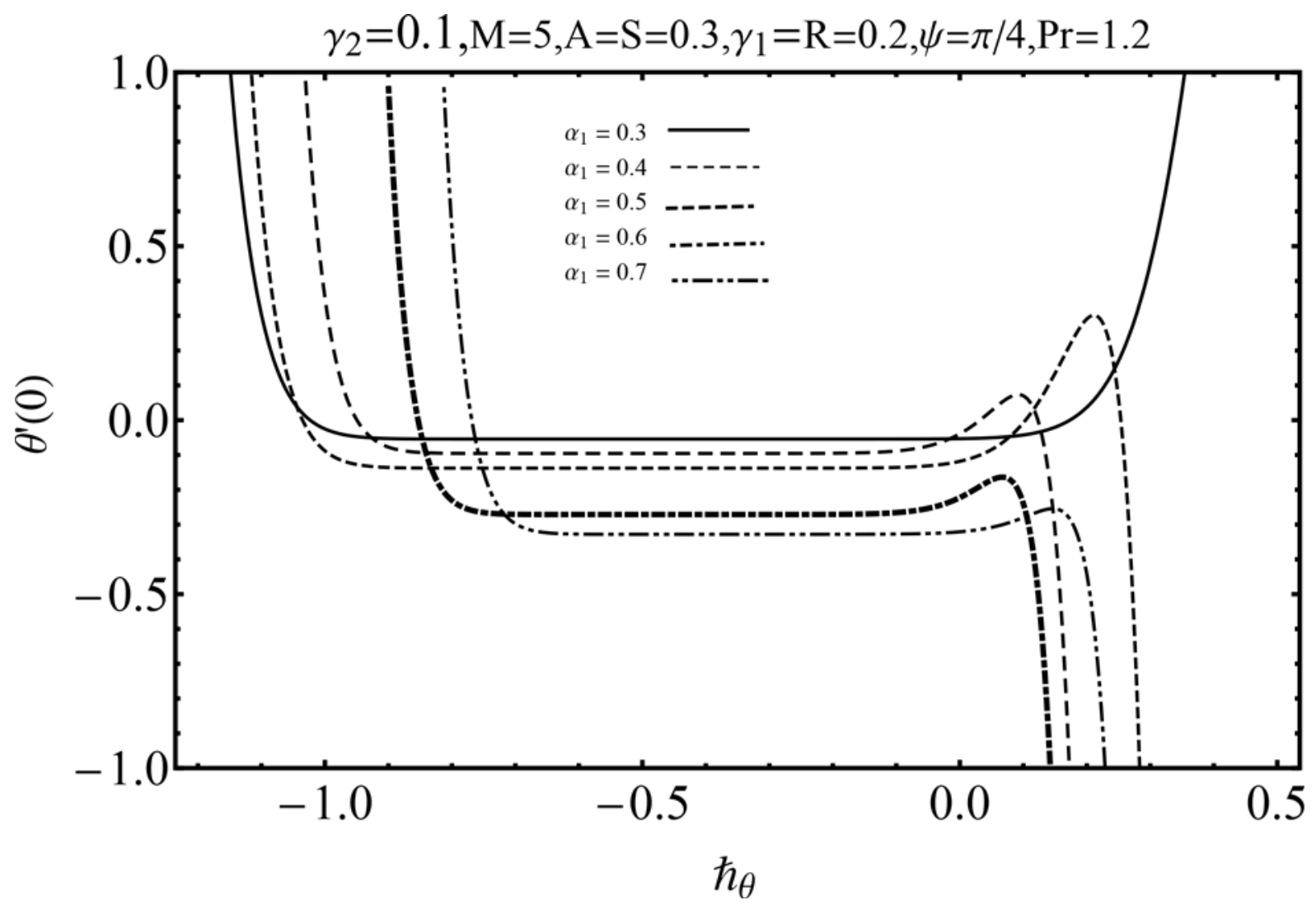

Fig 3. $\hbar$ - curve for $\theta^{\prime}(0)$ via various values of $\alpha_{1}$.

doi:10.1371/journal.pone.0152555.g003

magnetic parameter $M$, the velocity profile decreases near the porous walls where the suction effects are dominant when $\eta \leq 0.42$. However for $\eta>0.42$ the velocity profile increases. In fact the higher magnetic field slows down the fluid particles (because of the resistive force known as Lorentz force) and consequently the velocity distribution decreases. Fig 5 indicated the effects of magnetic parameter $M$ on $f(\eta)$ for the blowing case. This Fig depicts the opposite results in blowing situation. Influence of squeezing parameter $S$ on the velocity distribution for both cases of suction and blowing are shown in the Figs 8 and 9. It is analyzed that the velocity distribution $f(\eta)$ near the porous walls decreases and suction effects are dominant (see Fig 8). The flow enhances since upper wall is moving towards the stationary porous wall and pressure is

Table 1. Convergence of HAM solutions for different order of approximations when $M=5, S=A=0.3$, $\alpha_{1}=\gamma_{2}=0.1, R=\gamma_{1}=0.2, \operatorname{Pr}=1.2$ and $\psi=\pi / 4$.

\begin{tabular}{ccr}
\hline Order of approximations & $\boldsymbol{f}^{\prime \prime}(\mathbf{0})$ & $\boldsymbol{-}$ \\
\hline 1 & 1.460023 & 0.066542 \\
4 & 1.387792 & 0.066097 \\
6 & 1.388400 & 0.066093 \\
8 & 1.388285 & 0.066093 \\
12 & 1.388285 & 0.066093 \\
20 & 1.388285 & 0.066093 \\
\hline 30 & 1.388285 & 0.066093 \\
\hline 50 & 1.388285 & 0.066093 \\
\hline
\end{tabular}

doi:10.1371/journal.pone.0152555.t001 


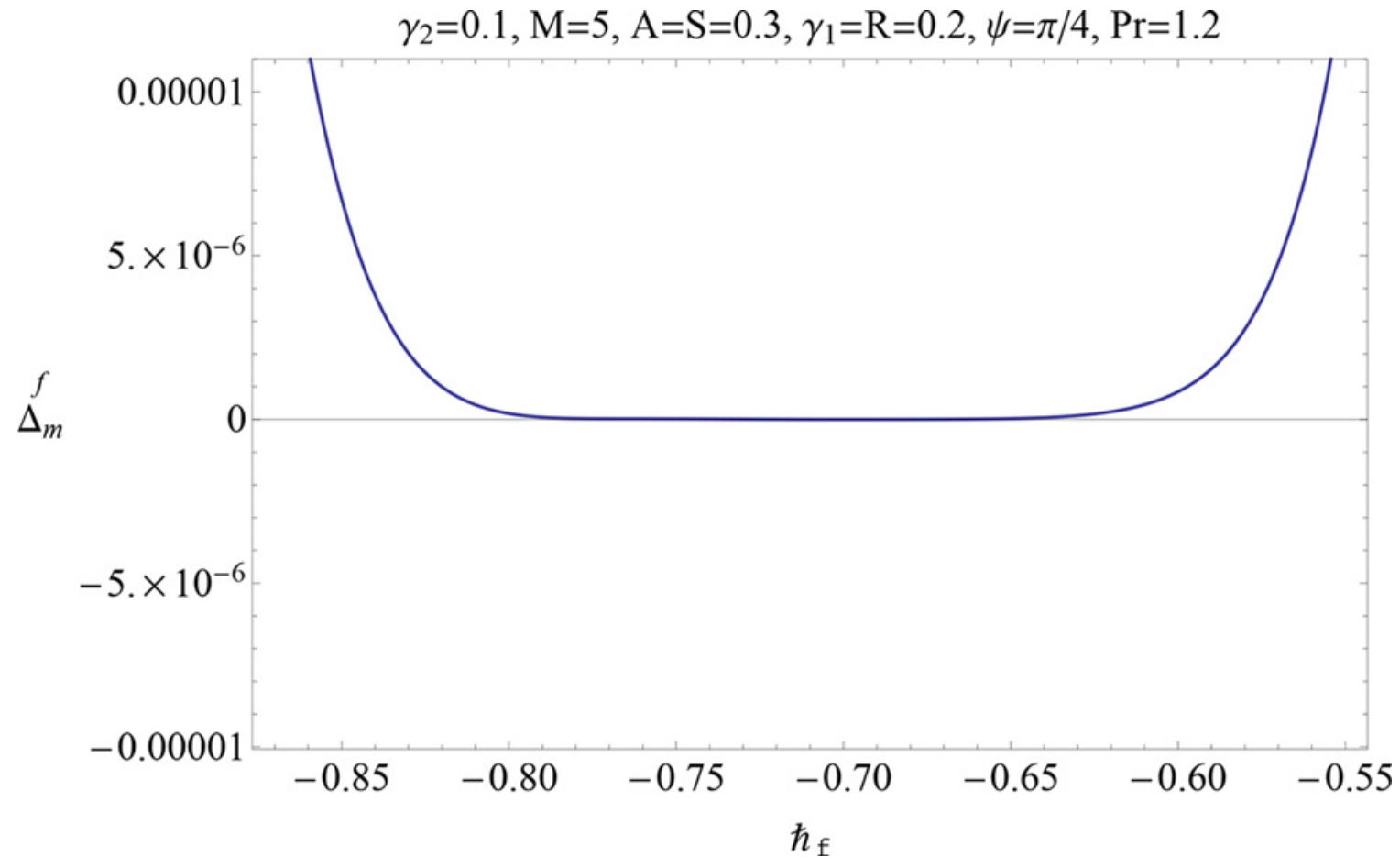

Fig 4. Residual error for $\hbar_{f}$.

doi:10.1371/journal.pone.0152555.g004



Fig 5. Residual error for $\hbar_{\theta}$.

doi:10.1371/journal.pone.0152555.g005 


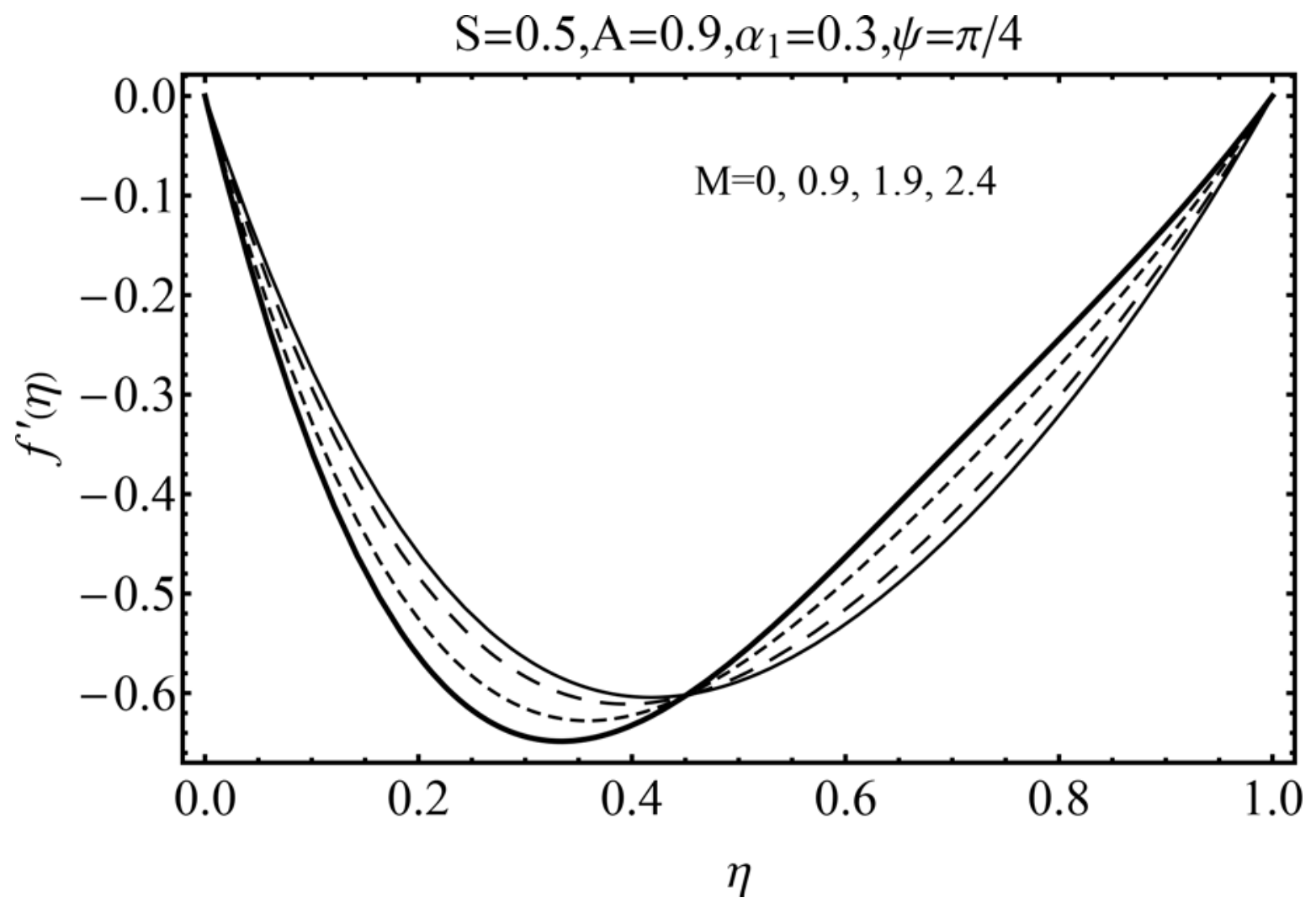

Fig 6. Influence of $M$ on $\boldsymbol{f}^{\prime}(\eta)$ for suction.

doi:10.1371/journal.pone.0152555.g006

produced. Therefore velocity distribution near the upper wall enhances in order to satisfy the mass conservation. Fig 9 indicated the effect of squeezing parameter $S$ on the velocity distribution for case of blowing $(A<0)$. Fluid velocity is reduced due to the fact that lower wall acts as a retarding force in case of blowing $(A<0)$. On the other hand fluid velocity enhances in the upper half region of the channel. In fact in upper half channel the squeezing effects are dominant. Figs 10 and 11 display the influence of fluid parameter $\alpha_{1}$ and angle of inclination $\psi$ on velocity distribution $f(\eta)$. It is noted that velocity distribution $f(\eta)$ increases near the porous wall when $\eta \leq 0.43$ whereas it decreases when $\eta>0.43$ for higher values of fluid parameter $\alpha_{1}$. In fact $\alpha_{1}$ is inversely proportional to the viscosity. For larger fluid parameter $\alpha_{1}$ the viscosity of fluid decreases and consequently the velocity distribution enhances. The behavior of angle of inclination $\psi$ on the velocity profile $f(\eta)$ is illustrated in Fig 11 . Here, $f(\eta)$ increases gradually when $\psi$ enhances but there is a decrease in $f(\eta)$ when $0.4 \leq \eta \leq 1$. It is due to the fact that by increasing angle of inclination $\psi$ the influence of magnetic effects on fluid particle rises which enhances the Lorentz force. Therefore velocity distribution decreases. Also one can observed that $\psi=0$ is the case when magnetic effect has no influence on the velocity distribution. For $\psi=\pi / 2$ the fluid particles offered the maximum resistance.

\section{Temperature distribution}

Variation of magnetic parameter $(M)$ on the temperature distribution $\theta(\eta)$ is shown in Fig 12. It is noted that temperature distribution increases for higher magnetic parameter $M$. This is due to the fact that an increase in $M$ give rise to the resistive force (Lorentz force), and 


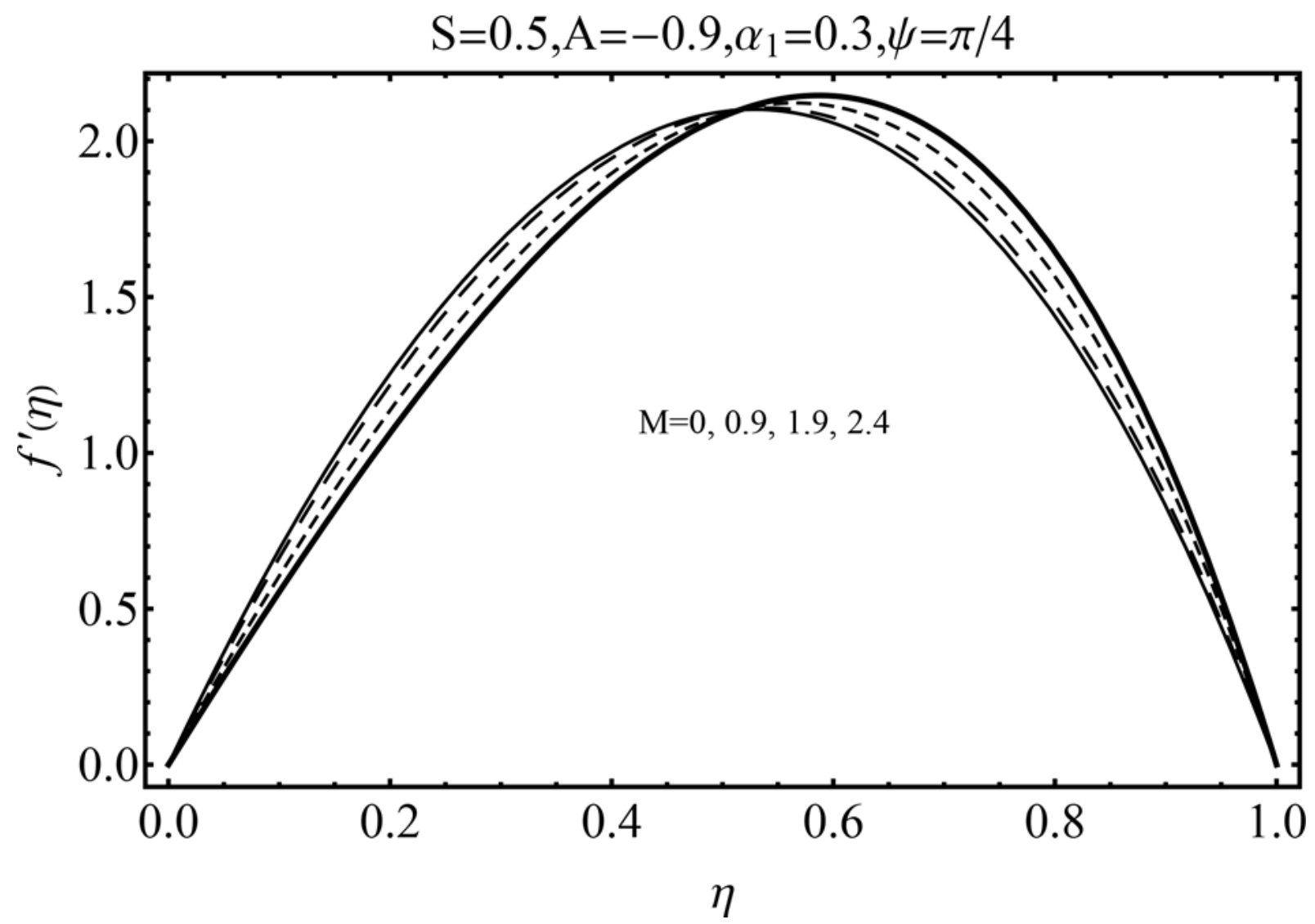

Fig 7. Influence of $M$ on $f^{\prime}(\eta)$ for blowing.

doi:10.1371/journal.pone.0152555.g007

consequently the temperature distribution increases. Fig 13 illustrates the effect of squeezing parameter $S$ on the temperature $\theta(\eta)$. This figure indicates that for larger values of squeezing parameter $S$ the temperature distribution decreases. Higher values of squeezing parameter $S$ indicate that kinematic viscosity decreases and depends upon the velocity and distance between disks. The effect of radiation parameter $R$ on the temperature distribution $\theta(\eta)$ is visualized in Fig 14 by keeping other parameters fixed. Temperature distribution is an increasing function of radiation parameter $R$. The mean absorption coefficient decreases for higher thermal radiation parameter $R$. Therefore temperature distribution increases. Fig 15 is sketched to examine the influence of Prandtl number Pr on temperature profile. It is contemplated that an increase in Pr reduce the thermal boundary layer due to which the heat transfer rate enhances and as a result the temperature of fluid decreases. Fig 16 demonstrates the influence of angle of inclination $(\psi)$ on temperature distribution $\theta(\eta)$. It is revealed that temperature profile $\theta(\eta)$ increases for higher values of inclination angle $\psi$. It is due to the fact that higher values of angle of inclination $\psi$ corresponds to larger magnetic field which opposes the fluid motion. As a result the temperature profile $\theta(\eta)$ increases. Figs 17 and 18 display the impact of Biot number $\left(\gamma_{1}, \gamma_{2}\right)$ on the temperature distribution $\theta(\eta)$. Fig 17 indicates the influence of Biot number $\left(\gamma_{1}\right)$ at the lower disk on temperature distribution. It is observed that larger $\gamma_{1}$ leads to an increase in the temperature profile $\theta(\eta)$ and thermal boundary layer thickness. The Biot number is the ratio of the internal resistance of a solid to the thermal resistance of the disk surface. With the increase of the Biot number, the thermal resistance of the surface of disk decreases. Higher surface temperature is achieved due to increase in convection which makes the thermal effect to go deep in 


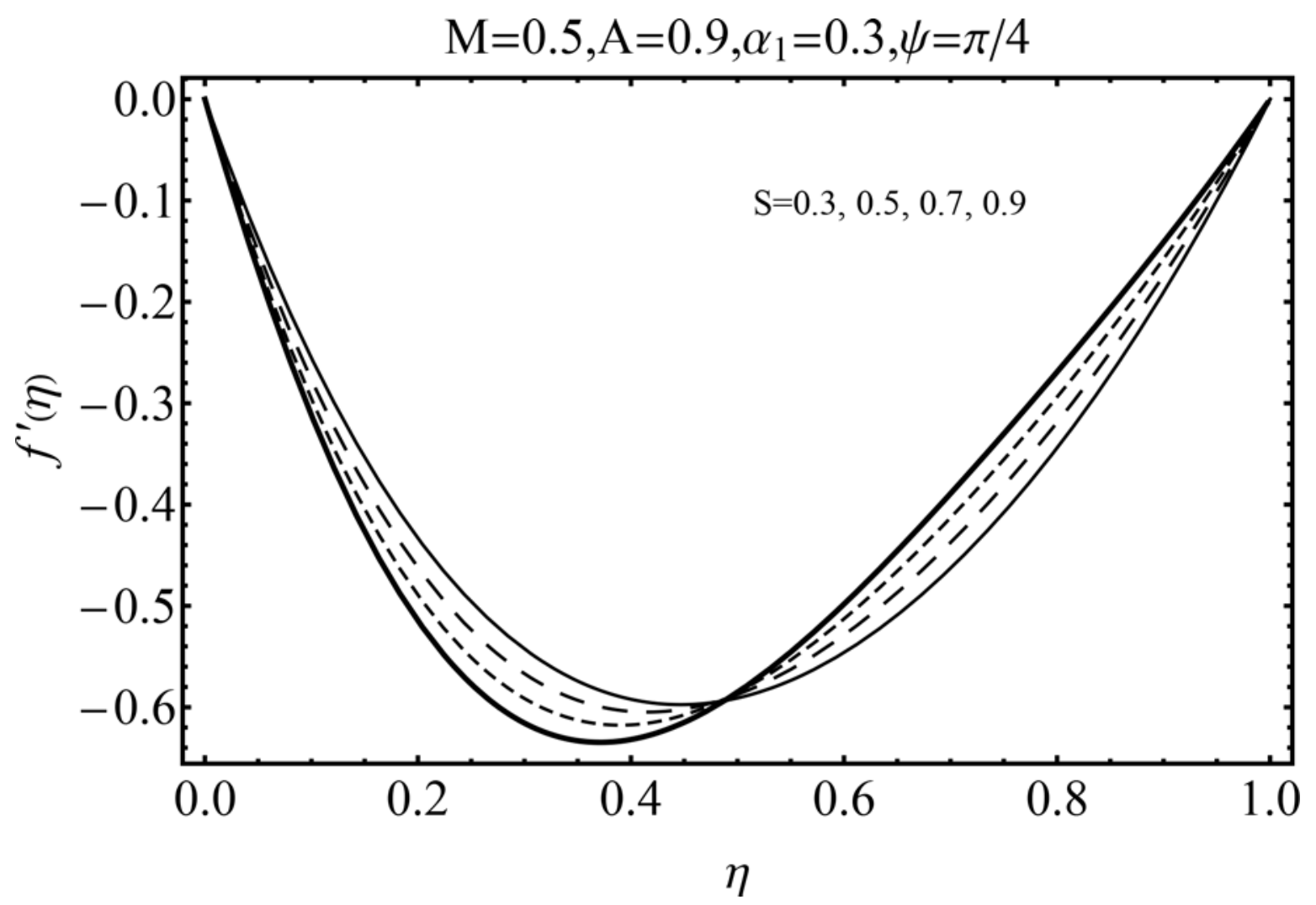

Fig 8. Influence of $S$ on $f^{\prime}(\eta)$ for suction.

doi:10.1371/journal.pone.0152555.g008



Fig 9. Influence of $S$ on $f^{\prime}(\eta)$ for blowing.

doi:10.1371/journal.pone.0152555.g009 


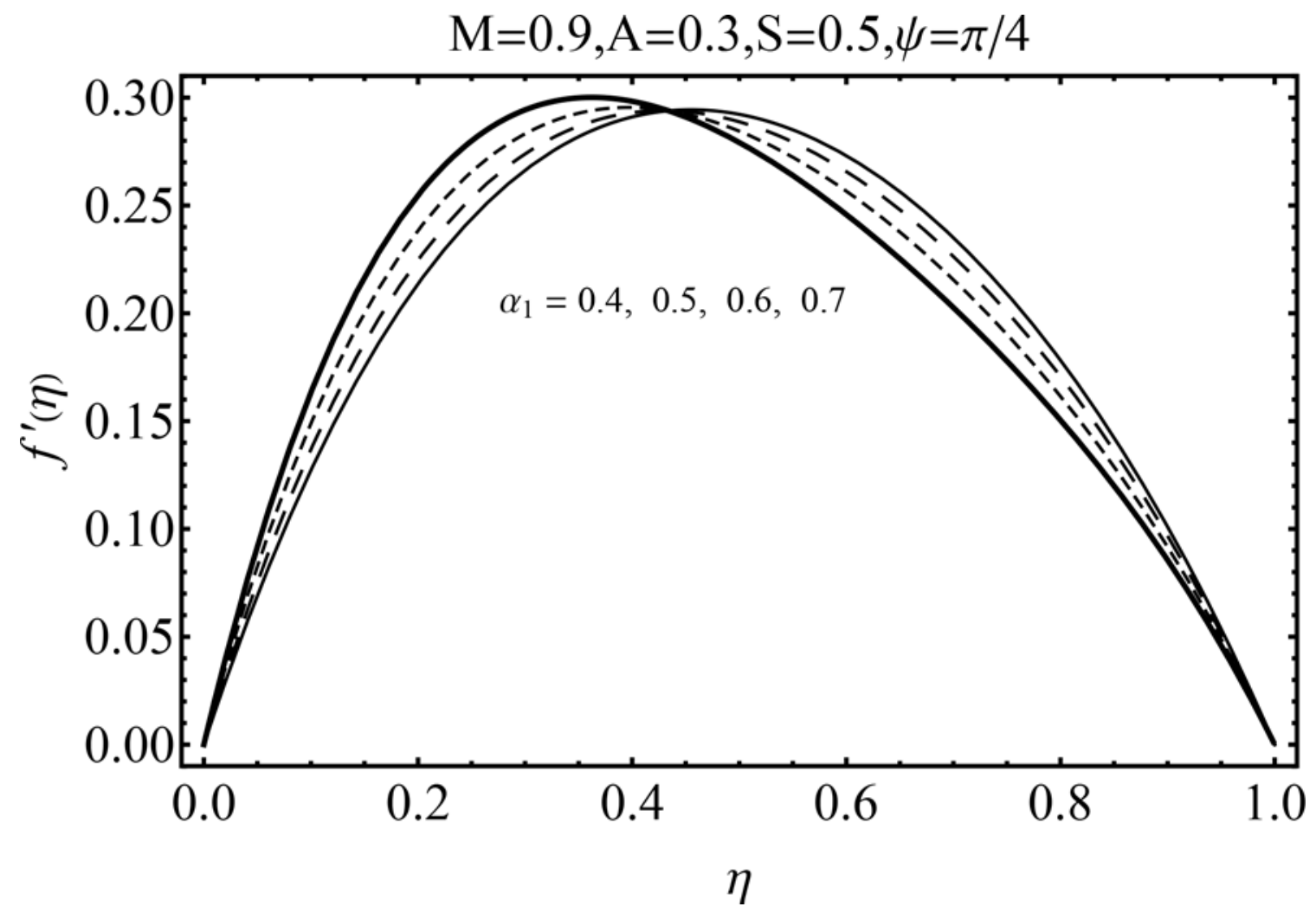

Fig 10. Influence of $\alpha_{1}$ on $f^{\prime}(\eta)$.

doi:10.1371/journal.pone.0152555.g010

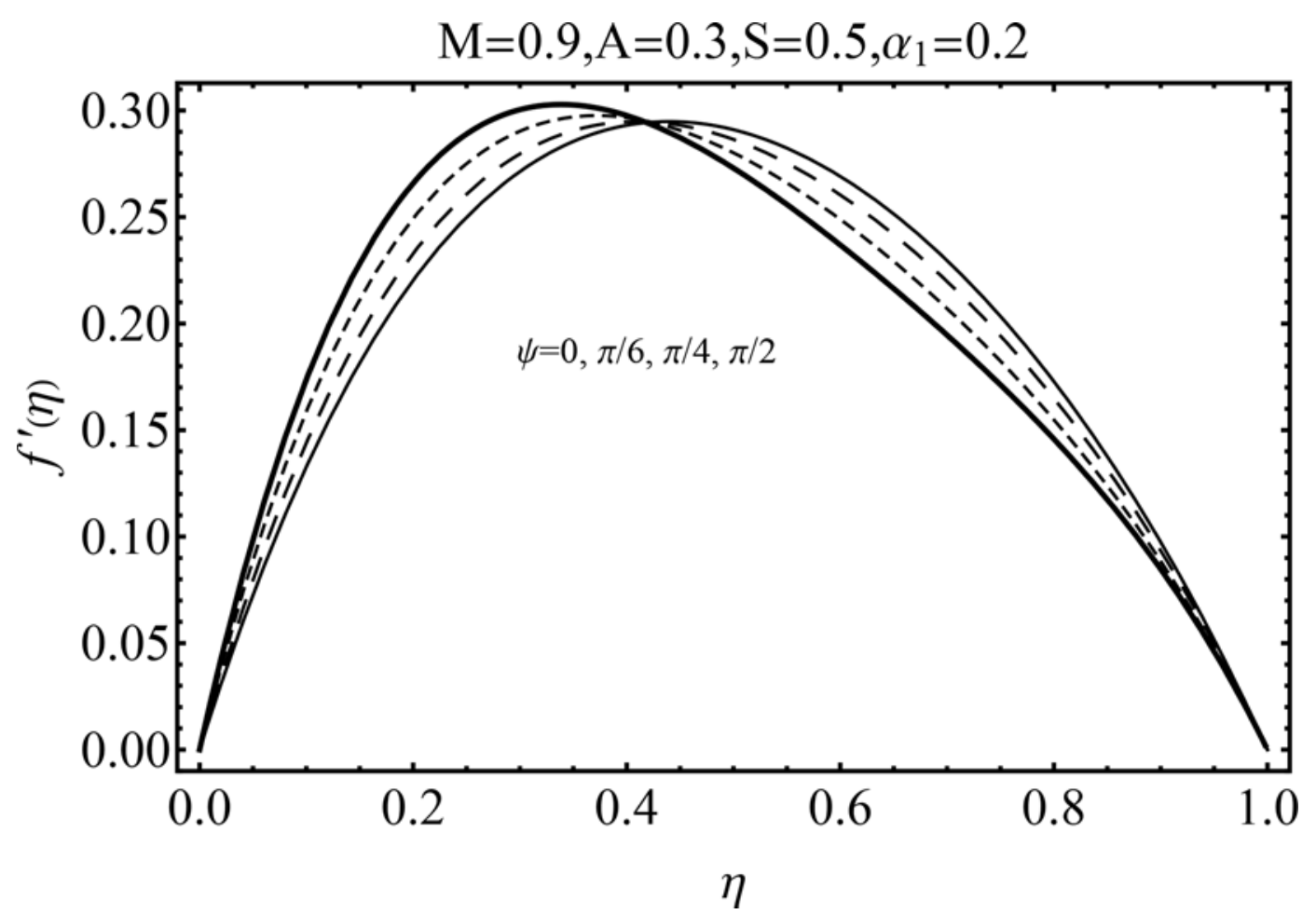

Fig 11. Influence of $\psi$ on $f^{\prime}(\eta)$.

doi:10.1371/journal.pone.0152555.g011 


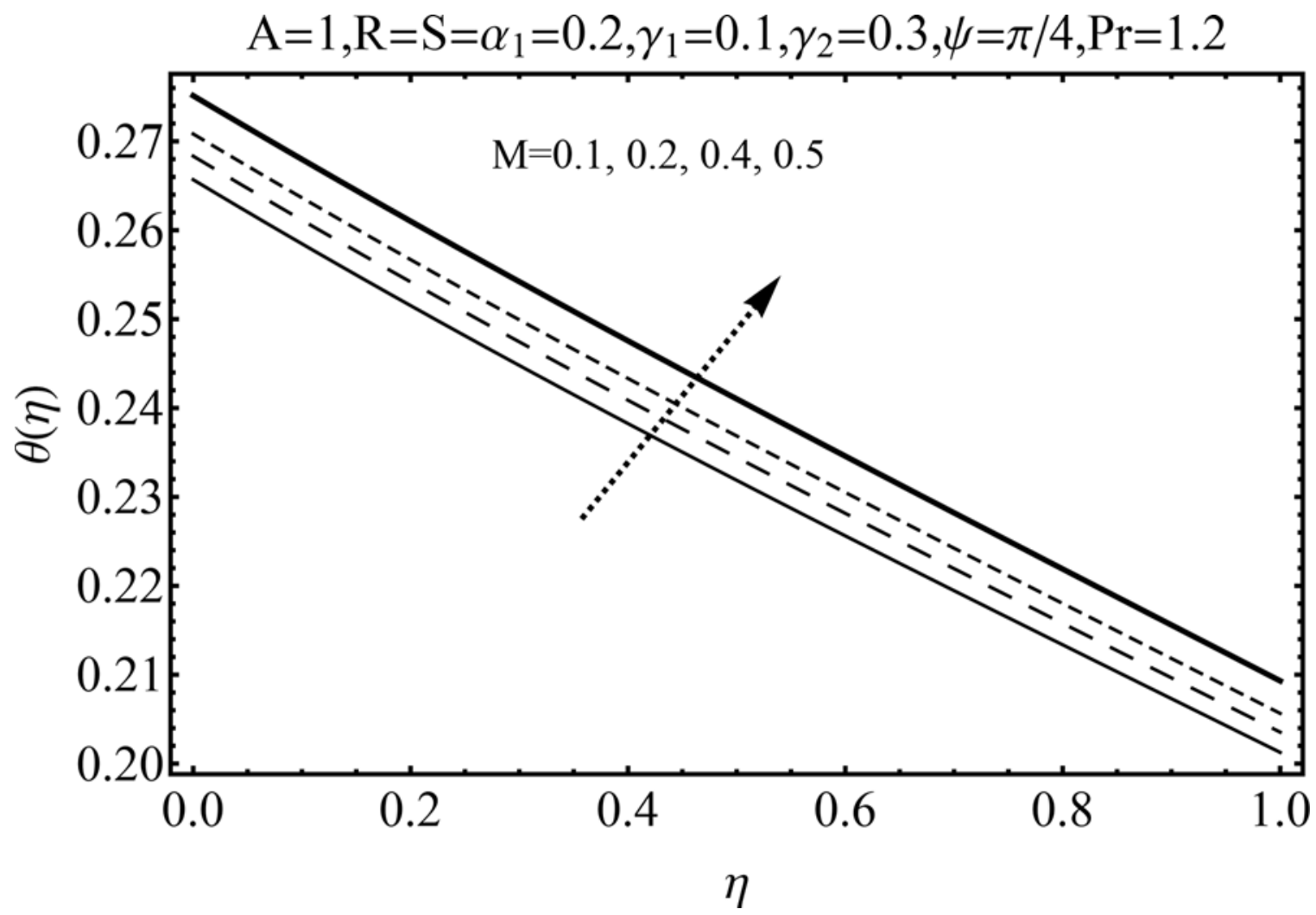

Fig 12. Influence of $M$ on $\theta(\eta)$.

doi:10.1371/journal.pone.0152555.g012

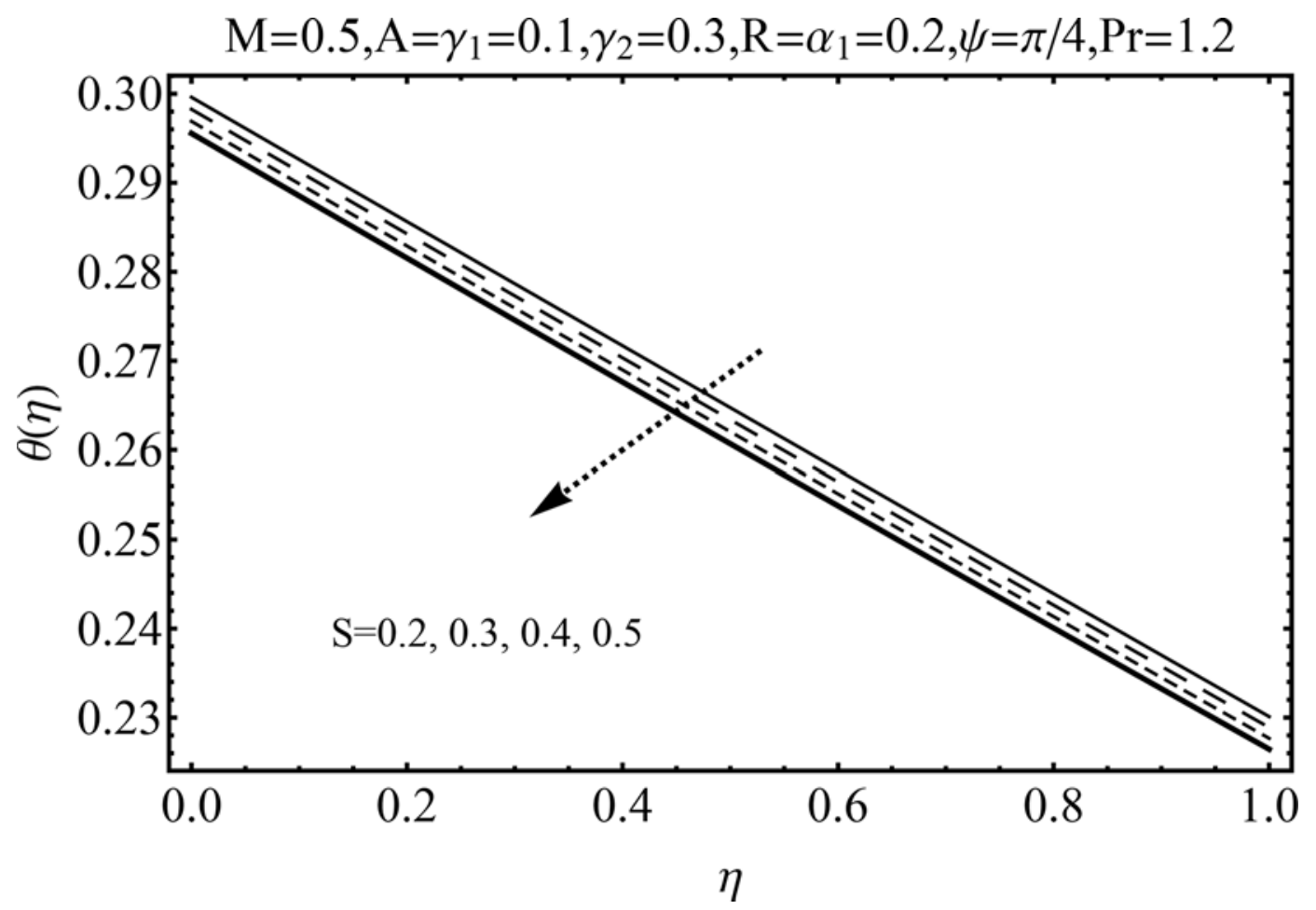

Fig 13. Influence of $S$ on $\theta(\eta)$.

doi:10.1371/journal.pone.0152555.g013 


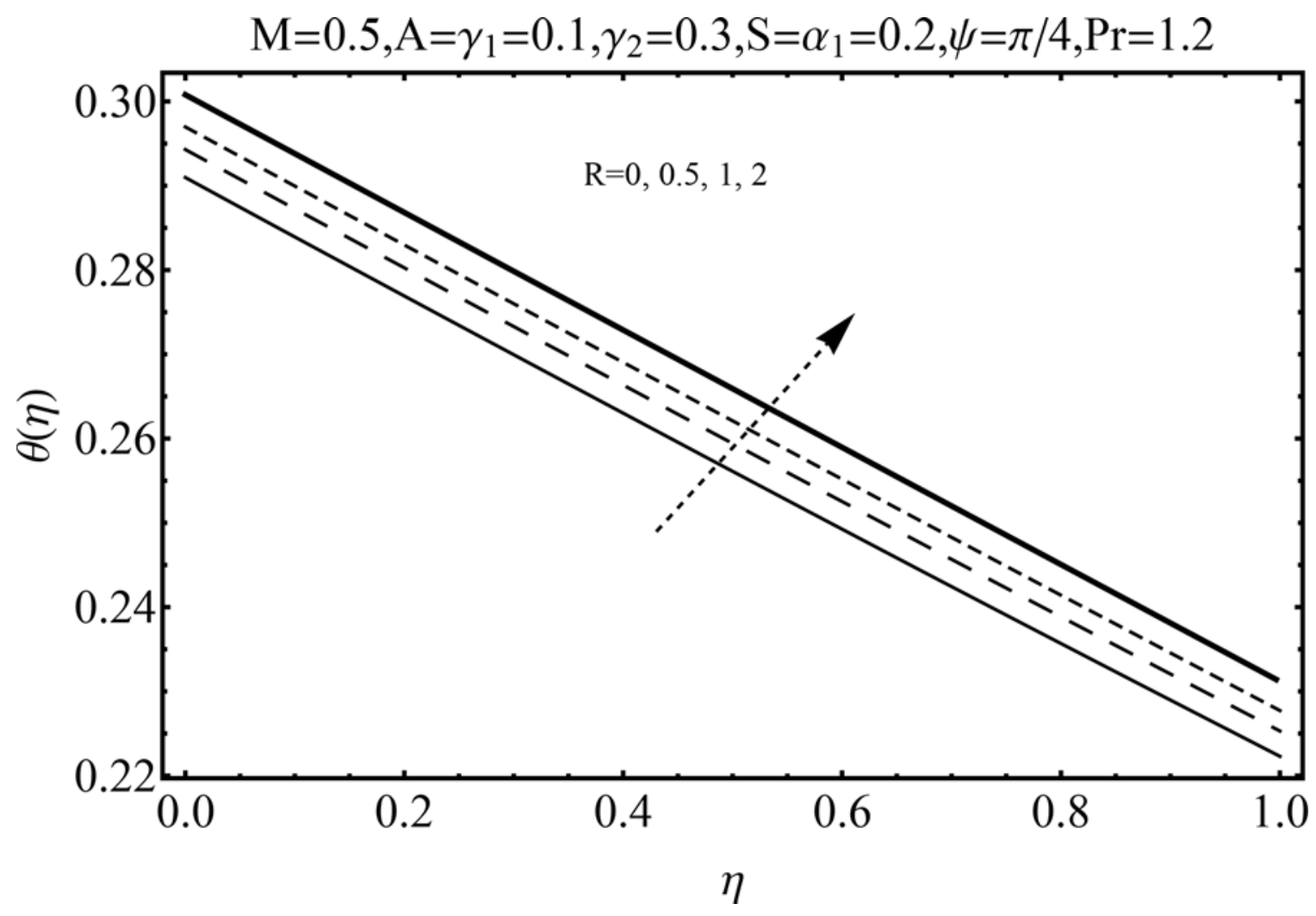

Fig 14. Influence of $R$ on $\theta(\eta)$.

doi:10.1371/journal.pone.0152555.g014

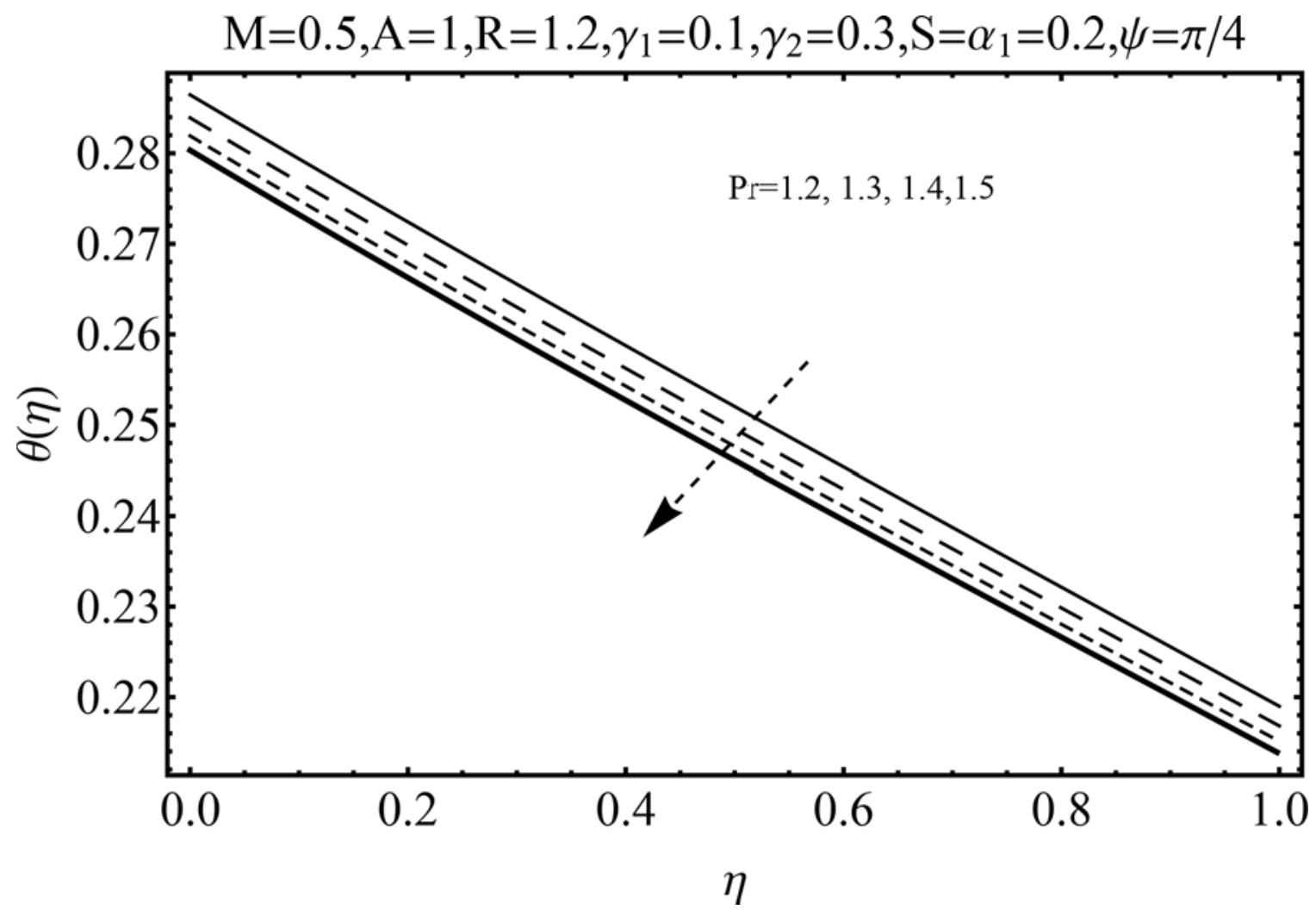

Fig 15. Influence of $\operatorname{Pr}$ on $\theta(\eta)$.

doi:10.1371/journal.pone.0152555.g015 


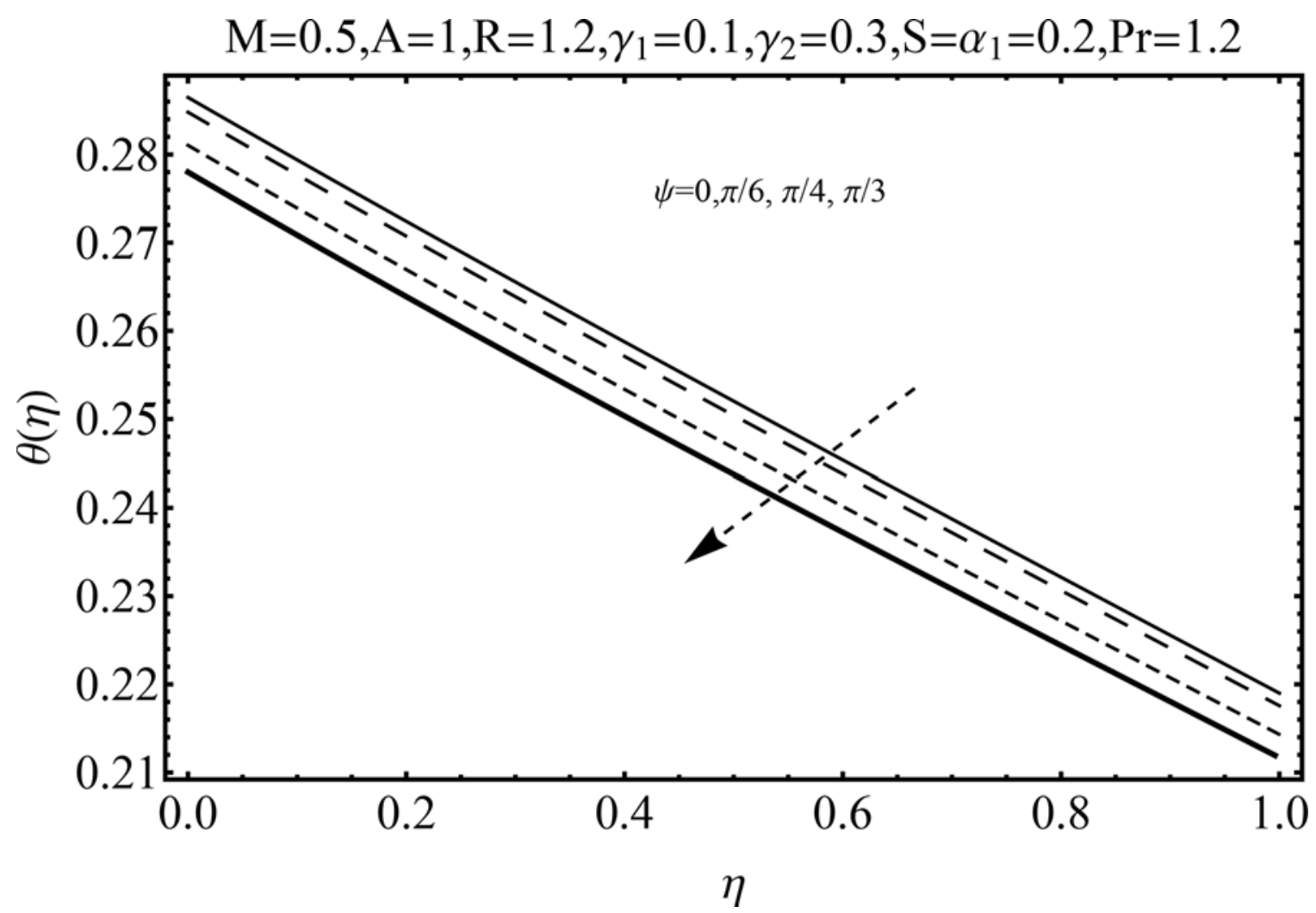

Fig 16. Influence of $\psi$ on $\theta(\eta)$.

doi:10.1371/journal.pone.0152555.g016



Fig 17. Influence of $\gamma_{1}$ on $\theta(\eta)$. 


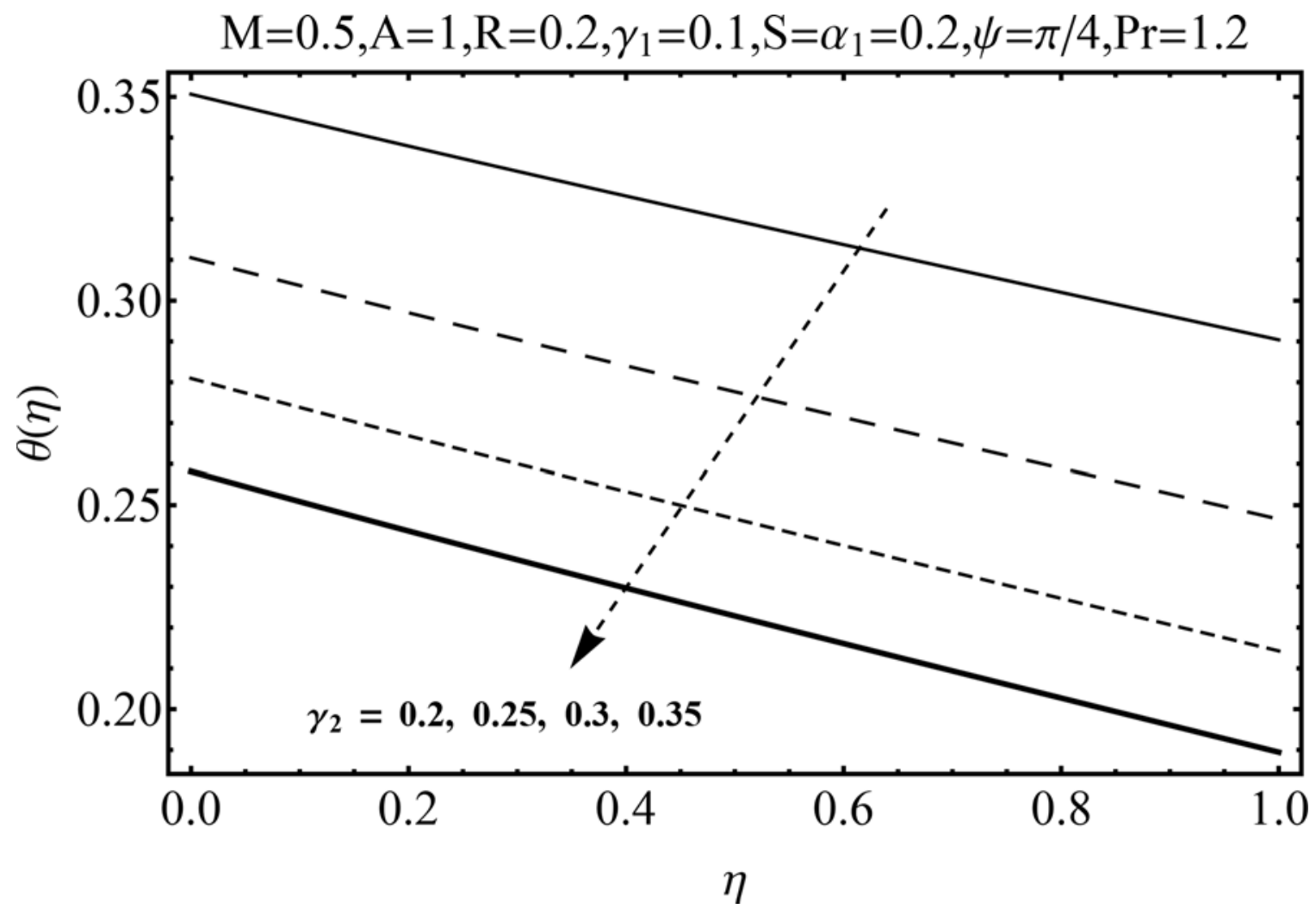

Fig 18. Influence of $\gamma_{2}$ on $\theta(\eta)$.

doi:10.1371/journal.pone.0152555.g018

to the quiescent fluid. Fig 18 is plotted for various values of Biot number $\gamma_{2}$ on temperature at the upper wall. It is noted that the fluid temperature decreases due to increasing convective heat loss at the upper disk.

\section{Skin Friction and local Nusselt number}

Table 2 shows the comparison of numerical values of $f^{\prime}(1)$ with Domairry and Aziz [17] and Hayat et al. [5] for different values of squeezing parameter $S$ and Hartman number $M$. It is observed that the present results are in excellent agreement with previous published data.

Table 2. Comparison between HAM and HPM in limiting situations for different values of squeezing parameter $S$ and Hartman number $M$ when other parameters are fixed.

\begin{tabular}{lcccc}
\hline $\mathbf{S}$ & $\mathbf{M}$ & \multicolumn{1}{c}{$\boldsymbol{f}^{\prime}(\mathbf{1})$} & \\
\cline { 3 - 5 } & & Hayat et al. [5] & Domairry and Aziz [8] & present work \\
\hline 0.1 & 1 & 3.02725 & 3.02725 & 3.02725 \\
0.2 & & 3.00560 & 3.00560 & 3.00560 \\
0.3 & 2.98468 & 2.98468 & 2.98468 \\
0.4 & & 2.96449 & 2.96449 & 2.96449 \\
0.1 & 0 & 2.97682 & 2.97682 & 2.97682 \\
& 1 & 3.02725 & 3.02725 & 3.02725 \\
& 2 & 3.17424 & 3.17424 & 3.17424 \\
& 3 & 3.40620 & 3.40620 & 3.40620 \\
\hline
\end{tabular}

doi:10.1371/journal.pone.0152555.t002 
Table 3. Numerical data of skin friction coefficient at upper and lower disks for different values of parameters.

\begin{tabular}{|c|c|c|c|c|c|c|}
\hline$A$ & $s$ & $M$ & $\alpha_{1}$ & $\boldsymbol{\Psi}$ & $\frac{H^{2}}{r^{2}} \mathbf{R e}{ }_{r} C_{f r 0}$ & $-\frac{H^{2}}{r^{2}} \mathbf{R e}_{r} C_{f r 1}$ \\
\hline 0.1 & 0.3 & 5 & 0.1 & $\pi / 3$ & 3.5198 & 3.4281 \\
\hline 0.2 & & & & & 2.7138 & 2.5778 \\
\hline 0.3 & & & & & 1.8575 & 1.7229 \\
\hline \multirow[t]{3}{*}{0.1} & 0 & 5 & 0.1 & $\pi / 3$ & 3.4803 & 3.4087 \\
\hline & 0.2 & & & & 3.5066 & 3.4217 \\
\hline & 0.4 & & & & 3.5329 & 3.4346 \\
\hline \multirow[t]{3}{*}{0.1} & 0.3 & 2 & 0.1 & $\pi / 3$ & 2.9686 & 2.8953 \\
\hline & & 3 & & & 3.1070 & 3.0302 \\
\hline & & 4 & & & 3.2928 & 3.2101 \\
\hline \multirow[t]{3}{*}{0.1} & 0.3 & 5 & 0.05 & $\pi / 3$ & 3.3130 & 3.2565 \\
\hline & & & 0.15 & & 3.7260 & 3.6008 \\
\hline & & & 0.16 & & 3.7672 & 3.6355 \\
\hline \multirow[t]{3}{*}{0.1} & 0.3 & 5 & 0.1 & $\pi / 6$ & 3.0888 & 3.0125 \\
\hline & & & & $\pi / 4$ & 3.3101 & 3.2268 \\
\hline & & & & $\pi / 2$ & 3.7193 & 3.6184 \\
\hline
\end{tabular}

doi:10.1371/journal.pone.0152555.t003

Table 3 is prepared for the numerical values of skin friction coefficient for both upper and lower disks for various values of physical parameters. Magnitude of skin friction coefficient is increased for larger values of $S, M, \alpha_{1}$, and $\psi$ at both upper and lower disks while it decreases for suction parameter $A$ at both the upper and lower disks. The rate of heat transfer enhances for $\operatorname{Pr}, R, S, \gamma_{1}$, and $\gamma_{2}$ at the lower disk. On the upper disk the rate of heat transfer decreases by increasing the values of $\operatorname{Pr}$ and $S$ while it increases for larger values of $R, \gamma_{1}$, and $\gamma_{2}$. Table 4 is drawn for the numerical values of local Nusselt number for the different physical parameters.

\section{Conclusions}

Impact of thermal radiation in the squeezing flow of second grade fluid with convective boundary condition is explored. The following points of presented analysis are worthmentioning.

Table 4. Numerical values of Nusselt number at both upper and lower disks for different values of parameters.

\begin{tabular}{|c|c|c|c|c|c|c|}
\hline Pr & $\boldsymbol{R}$ & $S$ & $Y_{1}$ & $V_{2}$ & $(1-a t)^{\frac{1}{2}} N u_{r 0}$ & $(1-a t)^{\frac{1}{2}} N u_{r 1}$ \\
\hline 1 & 0.2 & 0.3 & 0.2 & 0.1 & 0.080403 & 0.078528 \\
\hline 1.2 & & & & & 0.080652 & 0.078399 \\
\hline 1.3 & & & & & 0.080776 & 0.078335 \\
\hline \multirow[t]{3}{*}{1} & 0.3 & 0.3 & 0.2 & 0.1 & 0.088736 & 0.086861 \\
\hline & 0.4 & & & & 0.097069 & 0.095195 \\
\hline & 0.5 & & & & 0.105400 & 0.103530 \\
\hline \multirow[t]{3}{*}{1} & 0.2 & 0.4 & 0.2 & 0.1 & 0.080818 & 0.078313 \\
\hline & & 0.5 & & & 0.081235 & 0.078098 \\
\hline & & 0.6 & & & 0.081654 & 0.077882 \\
\hline \multirow[t]{3}{*}{1} & 0.2 & 0.3 & 0.7 & 0.1 & 0.103974 & 0.101549 \\
\hline & & & 0.8 & & 0.105521 & 0.103059 \\
\hline & & & 0.9 & & 0.106756 & 0.104266 \\
\hline \multirow[t]{3}{*}{1} & 0.2 & 0.3 & 0.2 & 0.3 & 0.137044 & 0.133847 \\
\hline & & & & 0.4 & 0.150277 & 0.146771 \\
\hline & & & & 0.6 & 0.166338 & 0.162458 \\
\hline
\end{tabular}

doi:10.1371/journal.pone.0152555.t004 
- Velocity profile decreases while the temperature distribution increases for larger magnetic parameter.

- Effects of angle of inclination, Prandtl number and magnetic parameter are qualitatively similar.

- Effect of Prandtl number on temperature field is opposite to that of thermal radiation parameter $R$.

- Temperature distribution enhances for larger radiation parameter $R$.

- Effects of magnetic and squeezing parameters on velocity distribution having similar behavior for both suction and blowing cases.

- Skin friction coefficient increases for higher values of $S, M, \alpha_{1}$, and $\psi$.

- For the larger values of $R, \gamma_{1}$, and $\gamma_{2}$ the magnitude of local Nusselt number increases at both upper and lower disks.

\section{Author Contributions}

Conceived and designed the experiments: TH SJ AS AA. Performed the experiments: TH SJ AS AA. Analyzed the data: TH SJ AS AA. Contributed reagents/materials/analysis tools: TH SJ AS AA. Wrote the paper: TH SJ AS AA.

\section{References}

1. Stefan MJ (1874) Versuch uber die scheinbare Adhasion, sitzungsber, Abt.II, Osterr.Akad.Wiss., MathNaturwiss.kl. 69, 713-721.

2. Mahmood M, Asghar S, Hossian MA (2007) Squeezed flow and heat transfer over a porous surface for viscous fluid. Int J Heat Mass Transfer, 44, 165-173.

3. Mustafa M, Hayat T, Alsaedi A (2012) On the analytical solutions for squeezing flow of nanofluid between parallel disks. Nonlinear Anal Model Control, 17, 418-430.

4. Qayyum A, Awais A, Alsaedi A, Hayat T (2012) Unsteady squeezing flow of a Jeffery fluid between parallel disks. Chin Phys Lett, 29, 034701.

5. Hayat $T$, Yuosaf $A$, Mustafa M, Obaidat S (2012) MHD squeezing flow of second grade fluid between two parallel disks. Int J Numer Methods Fluid, 69, 399-410.

6. Ganji DD, Abbasi M, Rahimi J, Gholami M, Rahimipetroudi I (2014) On the MHD squeeze flow between two parallel disks with suction or injection via HAM and HPM. Front Mech Eng, 9, 270-280.

7. Hayat T, Qayyum A, Alsaadi F, Awais M, Dobaie AM (2013) Thermal radiation effects in squeezing flow of a Jeffery fluid. Eur Phys J Plus, 128, 85.

8. Domairry G, Aziz A (2009) Approximate analysis of MHD squeeze flow between two parallel disks with suction or injection by homotopy perturbation method. Math Prob Eng, 2009, 603916.

9. Sheikholeslami M, Ellahi R (2015) Three dimensional mesoscopic simulation of magnetic field effect on natural convection of nanofluid. Int J Heat Mass Transf, 89, 799-808.

10. Sheikholeslami M, Vajravelu K, Rashidi MM (2016) Forced convection heat transfer in a semi annulus under the influence of a variable magnetic field. Int J Heat Mass Transf, 92, 339-348.

11. Sheikholeslami M, Kandelousi (2014) KKL correlation for simulation of nanofluid flow and heat transfer in a permeable channel. Physics Letters A, 378, 3331-3339.

12. Sheikholeslami M, Ganji DD (2015) Nanofluid flow and heat transfer between parallel plates considering Brownian motion using DTM. Comput Methods Appl Mech Eng, 283, 651-663.

13. Sheikholeslami M, Rashidi MM, Ganji DD (2015) Effect of non-uniform magnetic field on forced convection heat transfer of Fe3O4-water nanofluid. Comput Methods Appl Mech Eng, 294, 299-312.

14. Sheikholeslami M, Ganji DD (2014) Ferrohydrodynamic and magnetohydrodynamic effects on ferrofluid flow and convective heat transfer. Energy, 75, 400-410.

15. Sheikholeslami M, Ganji DD (2015) Entropy generation of nanofluid in presence of magnetic field using Lattice Boltzmann Method. Physica A, 417, 273-286. 
16. Sheikholeslami M, Abelman S (2015) Two-Phase simulation of Nanofluid flow and heat transfer in an annulus in the presence of an axial magnetic field. IEEE Transc Nanotech, 14, 561-569.

17. Sheikholeslami M, Rashidi MM (2015) Ferrofluid heat transfer treatment in the presence of variable magnetic field. Eur Phys J Plus, 130: 115.

18. Sheikholeslami M, Rashidi MM (2015) Effect of space dependent magnetic field on free convection of Fe304-water nanofluid. J Taiwan Inst Chem Eng, 56, 6-15.

19. Rashidi MM, Ferdows M, Parsa AB, Abelman S, (2014) MHD natural convection with convective surface boundary condition over a flat plate. Abs Appl Anal, 2014, 10.

20. Rashidi MM, Kavyani N, Abelman S, Uddin MJ, Freidoonimehr N (2014) Double diffusive magnetohydrodynamic (MHD) mixed convective slip flow along a radiating moving vertical flat plate with convective boundary condition. Plos One, 9, e109404. doi: 10.1371/journal.pone.0109404 PMID: 25343360

21. Bachok N, Ishak A, Pop I (2013) Stagnation point flow toward a stretching/shrinking sheet with a convective surface boundary condition. J Franklin Institute, 350, 2736-2744.

22. Hayat T, Shehzad SA, Alsaedi A (2014) MHD three-dimensional flow by an exponentially stretching surface with convective boundary condition. J Aerosp Eng, 27, 04014011.

23. Hayat $T$, Shehzad SA, Asghar S (2013) MHD flow of thixotropic fluid with variable thermal conductivity and thermal radiation. Walailak J Sci Tech, 10, 29-42.

24. Pal D (2013) Hall current and MHD effects on heat transfer over an unsteady stretching permeable surface with thermal radiation. Comput Math Applications, 66, 1161-1180.

25. Bhattacharyya K, Mukhopadhyay S, Layek GC, Pop I (2012) Effects of thermal radiation on micropolar fluid flow and heat transfer over a porous shrinking sheet. Int J Heat Mass Transfer, 55, 2945-2952.

26. Hayat T, Awais A, Asghar S (2013) Radiative effects in a three-dimensional flow of MHD Eyring-Powell fluid. J Egyptian Math Society, 21, 379-384.

27. Hayat $T$, Waqas M, Shehzad SA, Alsaedi A (2013) Mixed convection radiative flow of Maxwell fluid near stagnation point with convective condition. J Mech, 29, 403-409.

28. Bhattacharyya $\mathrm{K}$ (2013) MHD stagnation point flow of Casson fluid and heat transfer over a stretching sheet with thermal radiation. J Thermodyn, 2013, 169674.

29. Sheikholeslami M, Ganji DD, Javed MY, Ellahi R (2015) Effect of thermal radiation on MHD nanofluid flow and heat transfer by means of two phase model. J Mag Mag Mat, 374, 36-43.

30. Liao SJ (2012) Homotopy analysis method in nonlinear differential equations, Springer \& Higher Education Press, 2012.

31. Hayat T, Shaheen U, Shafiq A, Alsaedi A, Asghar S (2015) Marangoni mixed convection flow with Joule heating and nonlinear radiation. AIP Advances 5, 077140.

32. Farooq U, Hayat $T$, Alsaedi A, Liao S (2014) Heat and mass transfer of two-layer flows of third-grade nano-fluids in a vertical channel. Appl Math Comput, 242, 528-540.

33. Noeiaghdam S, Zarei E, Kelishami HB (2015) Homotopy analysis transform method for solving Abel's integral equations of the first kind. Ain Shams Eng J, (in press).

34. Mirzaee F, Yari MK, Paripour M (2015) Solving linear and nonlinear Abel fuzzy integral equations by homotopy analysis method. J Taibah Uni Sci, 9, 104-115.

35. Hayat T, Shafiq A, Mustafa M, Alsaedi A (2015) Boundary-layer flow of Walters'B fluid with Newtonian heating. Zeitschrift für Naturforschung A, 70, 333-341.

36. Lin Y, Zheng L, Chen G (2015) Unsteady flow and heat transfer of pseudoplastic nanoliquid in a finite thin film on a stretching surface with variable thermal conductivity and viscous dissipation. Powder Technology, 274, 324-332.

37. Hayat T, Shafiq A, Alsaedi A (2015) MHD axisymmetric flow of third grade fluid by a stretching cylinder. Alex Eng J, 54, 205-212.

38. Shafiq A, Nawaz M, Hayat T, Alsaedi A (2013) Magnetohydrodynamic axisymmetric flow of a thirdgrade fluid between two porous disks. Braz J Chem Eng, 30, 599-609.

39. Sui J, Zheng L, Zhang X, Chen G (2015) Mixed convection heat transfer in power law fluids over a moving conveyor along an inclined plate. Int J Heat Mass Transfer, 85, 1023-1033.

40. Hayat T, Shafiq A, Alsaedi A, Asghar S (2015) Effect of inclined magnetic field in flow of third grade fluid with variable thermal conductivity. AIP Advances, 5, 087108. 